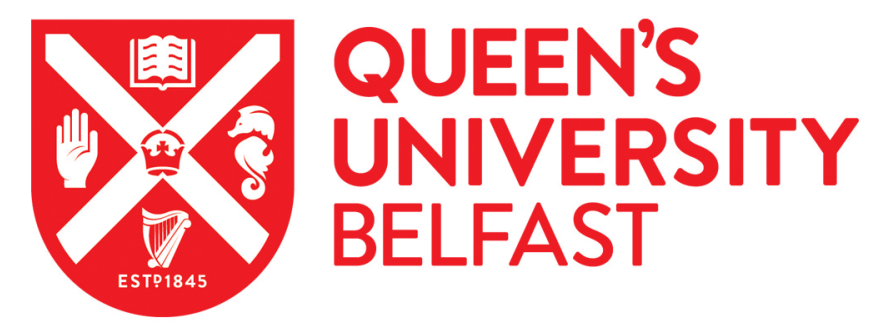

\title{
Experimental and numerical studies on the impact response of damage-tolerant hybrid unidirectional/woven carbon-fibre reinforced composite laminates
}

Liu, H., Falzon, B., \& Tan, W. (2018). Experimental and numerical studies on the impact response of damagetolerant hybrid unidirectional/woven carbon-fibre reinforced composite laminates. Composites Part B:

Engineering, 136(1), 101-118. https://doi.org/10.1016/j.compositesb.2017.10.016

Published in:

Composites Part B: Engineering

Document Version:

Peer reviewed version

Queen's University Belfast - Research Portal:

Link to publication record in Queen's University Belfast Research Portal

\section{Publisher rights}

Copyright 2017 Elsevier.

This manuscript is distributed under a Creative Commons Attribution-NonCommercial-NoDerivs License

(https://creativecommons.org/licenses/by-nc-nd/4.0/), which permits distribution and reproduction for non-commercial purposes, provided the author and source are cited.

\section{General rights}

Copyright for the publications made accessible via the Queen's University Belfast Research Portal is retained by the author(s) and / or other copyright owners and it is a condition of accessing these publications that users recognise and abide by the legal requirements associated with these rights.

\section{Take down policy}

The Research Portal is Queen's institutional repository that provides access to Queen's research output. Every effort has been made to ensure that content in the Research Portal does not infringe any person's rights, or applicable UK laws. If you discover content in the

Research Portal that you believe breaches copyright or violates any law, please contact openaccess@qub.ac.uk. 


\title{
Experimental and numerical studies on the impact response of damage-tolerant hybrid unidirectional/woven carbon-fibre reinforced composite laminates
}

\author{
Haibao Liua, Brian G. Falzona*, Wei Tan ${ }^{b}$ \\ a School of Mechanical and Aerospace Engineering, Queen's University Belfast, Ashby Building, Belfast BT9 5AH, UK \\ ${ }^{b}$ Engineering Department, University of Cambridge, Trumpington Street, Cambridge CB2 1PZ, UK
}

\section{ABSTRACT}

A woven Five-Harness Satin (5HS) weave with AS4 carbon fibres, and unidirectional high strength IMS60 carbon fibres were used to manufacture hybrid laminates, using resin infusion, to assess their performance in low velocity impact tests. Load/energy-time curves and load-displacement curves were extracted from the experimental data, and non-destructive Cscanning was performed on all pre- and post- impacted specimens to quantify the extent of damage incurred. A finite element-based computational damage model was developed to predict the material response of these hybrid unidirectional/woven laminates. The intralaminar damage model formulation, by necessity, consists of two sub-models, a unidirectional constitutive model and a woven constitutive model. The built-in surface-based cohesive behaviour in Abaqus/Explicit was used to define the interlaminar damage model for capturing delamination. The reliability of this model was validated using in-house experimental data obtained from standard drop-weight impact tests. The simulated reactionforce and absorbed energy showed excellent agreement with experiment results. The post-impact delamination and permanent indentation deformation were also accurately captured. The accuracy of the damage model facilitated a quantitative comparison between the performance of a hybrid unidirectional/woven (U/W) laminates and a pure unidirectional (PU) carbon-fibre reinforced composite laminates of equivalent lay-up. The hybrid laminates were shown to yield better impact resistance.

Key words: A: Laminates; B. Impact behaviour; C. Finite element analysis; D. Non-destructive testing;

\section{Introduction}

Carbon Fibre Reinforced Polymers (CFRPs) have been widely adopted in modern high performance lightweight structures. The main advantages of composite materials include high specific strength, stiffness and good fatigue resistance [1-3]. 
These excellent mechanical properties have made composites the pre-eminent material in the primary structure of the latest generation of passenger aircraft, such as the Boeing 787 and Airbus A350, where composites account for around $50 \%$ of the aircraft's weight. However, the superior properties of CFRP laminates tend to be in the fibre direction and actually exhibit very low strength and fracture toughness through the thickness direction [4-6]. As a consequence, low velocity impact is a critical load case for composite aerostructures. Delamination, matrix cracks and fibre breakage, resulting from an impact event, may significantly reduce the residual strength of composite structures $[7,8]$.

For this reason, studies associated with low velocity impact on composites attract a great deal of attention $[9,10]$. In order to attain a comprehensive understanding of the failure mechanisms, a number of experimental investigations have been conducted by researchers. Mehmet et al. [11] investigated the impact response of cross-ply and angle-ply glass/epoxy laminates under different impact energy levels. Due to the optically transparent nature of glass-epoxy composites, the damage modes and damage process were easily observed and discussed. They found that lower impact energies induced more delamination and matrix cracking, while, the higher impact energies resulted in more fibre failure. In the study presented by Celal and Mufit [12], different types of composites specimens; unidirectional E-Glass, woven E-Glass and woven aramid composite specimens, were tested under low velocity impact. Based on experimental results, the damage growth in woven composites was constrained within a smaller area compared with unidirectional composites, and shown to have superior damage resistance than unidirectional composites.

In order to mitigate extensive physical testing, it is also essential and practical to improve the capability to predict damage in composite laminates due impact. Some finite element-based composite damage models are available in commercial packages. Examples include the Abaqus built-in progressive composite damage model based on the work by Matzenmiller et al. [13]; and the LS-DYNA [14] material model type 262 which uses an approach based on the failure criteria presented by Chang and Chang [15]. Despite the widespread application of these commercial packages, calibration of non-physical parameters to control the damage propagation, is generally required.

Y. Shi et al. $[16,17]$ used stress-based criteria and fracture mechanics techniques to capture composite laminate damage initiation and evolution of damage during an impact event. The nonlinear shear properties of composites were defined by a semi-empirical shear stress-strain relationship. X-ray radiography was used to validate the proposed numerical model. Ansari and Chakrabarti [18] conducted a numerical investigation on the penetration and perforation behaviour of composite laminates under impact loading. The effects of boundary conditions and thickness-to-span ratio were discussed. Donadon et 
al. [19,20], Faggiani et al. [21] and Falzon et al. [22,23] proposed a three-dimensional (3D) computational damage mechanics (CDM) based material damage model to capture the intralaminar degradation of composite laminates with nonlinear shear behaviour. This model was combined with cohesive elements to investigate impact damage. Bouvet et al. $[7,24]$ presented a model which captured the permanent indentation caused by low velocity/low energy impact, similar to that reported by Faggiani [21]. Recently, a computational model was developed by Tan et al. [25-27] for predicting the material response of composite laminates under compressive, impact or crush loading. The intralaminar damage model, which accounts for physically-based failure mechanisms associated with the fibres and matrix, was implemented as a user subroutine in Abaqus/Explicit. The in-built cohesive behaviour [28] in Abaqus/Explicit was employed to capture the interlaminar failure.

In addition, damage models have been developed to specifically capture the material response of woven composite laminates. Zhong et al. [29] proposed a continuum damage model for predicting the damage initiation and development in 3D woven composites. The fibre damage was considered at the level of the fibre yarn, and a series of variables were defined to characterise the fibre and matrix failure modes. This damage model was implemented within the finite element method, and validated the quasi-static tensile experiments of a type of 3D woven composite. A 3D micromechanical model was developed by Donadon et al. [30] to predict the elastic behaviour of woven laminates. Composite laminates including a hybrid plain-weave with different materials and undulations in the warp and weft directions were manufactured and tested under tension and in-plane shear loading to validate the model.

In spite of extensive research in this area, there is still considerable work to be done to understand the intrinsic characteristics of a composite's response to low velocity impact. In this study, the impact response of carbon fibre/epoxy laminates with different lay-up was investigated using a drop-weight impact testing machine. The American Society for Testing Material (ASTM) D7136/D7136M standard was adopted in this study. Following the drop-weight impact tests, preliminary visual observation was performed on the top (impacted) and bottom surfaces of all specimens. These specimens were subsequently scanned using a C-scan system to obtain damage maps [7,8,24,31]. Specimen cross-sections along the $0^{\circ}, 45^{\circ}$ and $90^{\circ}$ fibre directions were extracted from selected impacted specimens for optical microscopy [32-34]. The microscopic analysis yielded further insight into composite damage arising from low velocity impact. A physically-based composites damage model, which accounts for material shear nonlinearity and damage mode interaction, was validated to predict the impact response of hybrid unidirectional/woven carbon fibre reinforced epoxy composite laminates. The in-plane damage in the warp and weft directions of the woven composites was defined by a fibre-dominated failure mode. A matrix- 
dominated failure mode was used to initiate the through-thickness damage of woven composites and the transverse damage of unidirectional composites. This model is shown to be able to reproduce the laminate's impact response and yield accurate results without calibrating any of the input material parameters obtained from standard physical tests [26]. This enabled the computational model to attain a truly and reliably predictive capability. The predictive results delivered by this damage model are shown to be in excellent agreement with experimental results.

\section{Material and specimen}

The materials used in this study were IMS60 unidirectional carbon fibre, five harness satin (5HS) woven AS4 carbon fibre fabric and an epoxy resin (propriety information). The panels, from which the specimens were produced, were manufactured using Resin Infusion under Flexible Tooling (RIFT) [35-37]. A flow distribution medium was used on the upper and lower surfaces of the preform to ensure complete wetting. All panels were subsequently inspected using C-scanning to ensure the pristine specimens were free of any major defect [38]. The material properties of the manufactured laminates were obtained using standard testing methods and are presented in Table 1.

\section{Table 1}

Mechanical properties of IMS60/Epoxy unidirectional (UD) lamina and AS4/Epoxy five harness satin (5HS) woven lamina

\begin{tabular}{llll}
\hline Materials & Modulus $(\mathrm{GPa})$ & Poisson`s ratio & Strength (MPa) \\
\hline Unidirectional & $E_{11}=152 ; E_{22}=E_{33}=8.71 ;$ & $v_{12}=v_{13}=0.3 ;$ & $X^{T}=1930 ; X^{C}=962 ;$ \\
lamina & $G_{12}=G_{13}=4.14 ; G_{23}=3.23 ;$ & $v_{23}=0.35 ;$ & $Y^{T}=41.4 ; Y^{C}=276 ;$ \\
& & & $S_{12}=82.1 ;$ \\
5HS woven & $E_{11}=E_{22}=65.4 ; E_{33}=8.71 ;$ & $v_{13}=v_{23}=0.33 ;$ & $X^{T}=Y^{T}=862 ;$ \\
lamina & $G_{13}=G_{23}=3.27 ; G_{12}=3.59 ;$ & $v_{12}=0.04 ;$ & $X^{C}=Y^{C}=689 ;$ \\
& & & \\
\end{tabular}

Specimens were cut from the RIFT-manufactured panels according to the ASTM D7136/D7136M testing standard. The geometric parameters and lay-up of the specimens used for low velocity impact tests are shown in Table 2. 


\section{Table 2}

Lay-up of the specimens for impact tests

\begin{tabular}{llc}
\hline Lay-up ID & Lay-up & Panel ID \\
\hline A & {$[5 H S /-45 /+45 / 90 / 0 /-45 /+45 / 90 /+45 /-45 / 90 /+45 /-45 / 0 / 90 /+45 /-45 / 5 H S]$} & P\#1 \\
B & {$[5 H S / 0 / 0 /+45 /-45 / 0 / 0 / 0 /-45 /+45 / 0 / 0 / 0 /+45 /-45 / 0 / 0 / 5 H S]$} & P\#2
\end{tabular}

a The nominal thickness of a unidirectional single ply and a $5 \mathrm{HS}$ single ply is $0.267 \mathrm{~mm}$ and $0.35 \mathrm{~mm}$, respectively.

\section{Experimental set-up}

The impact tests were carried out using an Instron-Dynatup $9250 \mathrm{HV}$ with a hemispherical $\emptyset 12.7 \mathrm{~mm}$ instrumented $6.4 \mathrm{~kg}$ steel impactor. The impact energy was adjusted through changing the height of the impactor drop [5]. Each specimen was positioned on a rigid support platform and fixed by four corner clamps with rubber tips to avoid specimen slippage under impact $[39,40]$. The test set-up is shown in Figs. 1a and $1 \mathrm{~b}$.

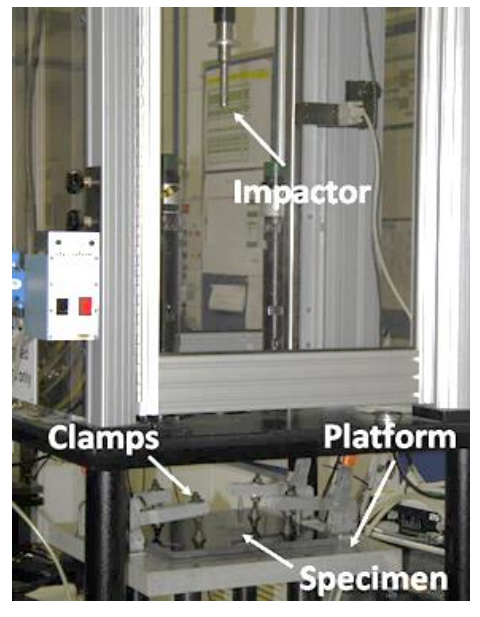

(a)

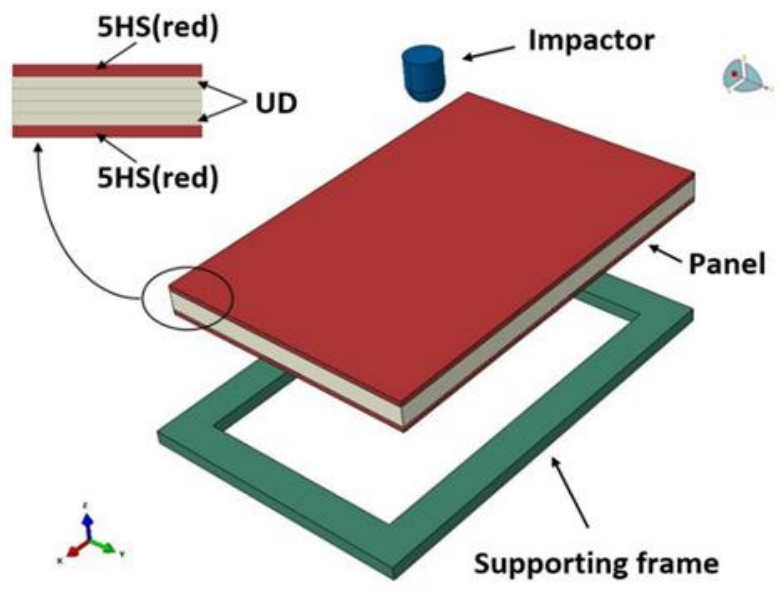

(b)

Fig. 1. (a) Experiment set-up and (b) schematic of test fixture for low velocity impact tests.

In order to investigate the effects of impact energy and lay-up on the response of the composite laminates subjected to damage-inducing loads, specimens with different lay-up were prepared, and tested under different impact energy as shown in Table 3. 


\section{Table 3}

Nominal geometric specimen parameters and testing conditions for drop-weight impact tests

\begin{tabular}{ccccccc}
\hline Panel No. & Sample No. & Lay-up & Nominal impact energy $(\mathrm{J})$ & Length $(\mathrm{mm})$ & Width (mm) & Thickness (mm) \\
\hline \multirow{2}{*}{ P\#1 } & $1,2,3$, & A & 25 & 150 & 100 & 4.78 \\
& $4,5,6$, & A & 17 & 150 & 100 & 4.78 \\
& $7,8,9$, & A & 10 & 150 & 100 & 4.78 \\
\hline \multirow{2}{*}{ P\#2 } & $1,2,3$, & B & 25 & 150 & 100 & 4.78 \\
& $4,5,6$, & B & 17 & 150 & 100 & 4.78 \\
& $7,8,9$, & B & 10 & 150 & 100 & 4.78 \\
\hline
\end{tabular}

Following the drop-weight impact test, a portable Rapid2 C-scan system, as shown in Fig. 2a, was used to perform the nondestructive inspection on all post-impact specimens. Before inspection, the C-scan system was calibrated to ensure the accuracy of scanning results. An illustration of the working of the C-scan system is shown in Fig. 2b. After the nondestructive inspection, a selection of impacted specimens was sectioned for microscopic analysis.

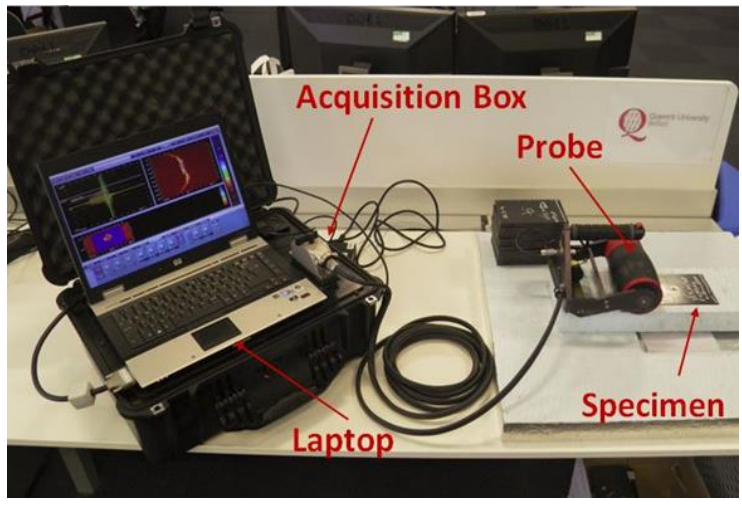

(a)

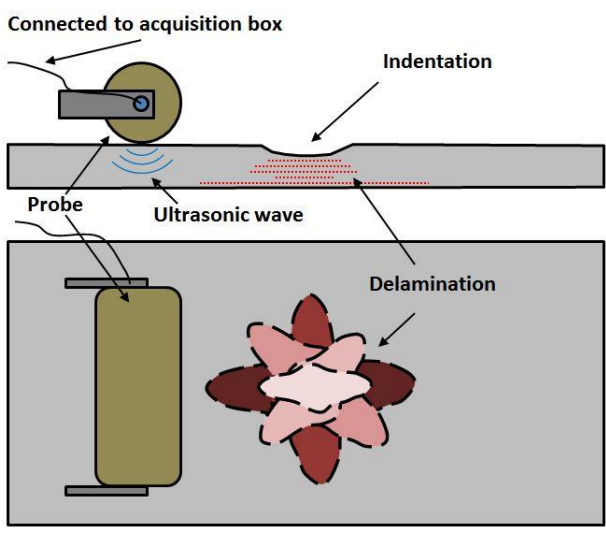

(b)

Fig. 2. (a) Portable Rapid2 C-scan system and (b) illustration of working theory.

\section{Experimental results and discussion}

4.1 Drop-weight impact tests 
The measured reaction force of the impactor and the instantaneous energy absorbed by the specimen, calculated from the velocity and mass of the impactor, were used to generate the load/energy-time curves. Typical load/energy-time curves, for each configuration, are shown in Figs. 3a and 3b (with reference to Fig.22 and Fig. 23, a high level of consistency was achieved in the load/energy-time curves obtained from sets of samples with the same configuration and under the same testing conditions). The peak load was observed to increase with the growth of impact energy. In the load-time curves (black curves in Figs. 3a and 3b), the initial increase in load is due to the elastic response of the specimens under impact loading. This is followed by a dip in loading, corresponding to initial damage. Delamination and matrix cracking, caused by impact, start to propagate beyond this point. The rebounding of the impactor is reproduced by the smooth reduction in the reaction force measured from the impactor. The energy absorbed by the composite laminates is the difference between the initial impact energy and the kinetic energy of the impactor. The red curves in Figs. 3a and 3b indicate the absorbed energy over time. The resulting plateau in the absorbed energy-time curve represents the energy absorbed by the composite laminates, primarily dissipated through the creation of damage.

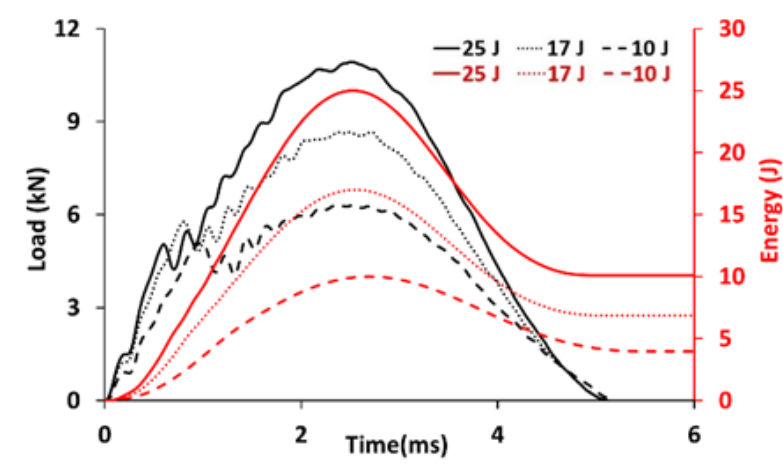

(a)

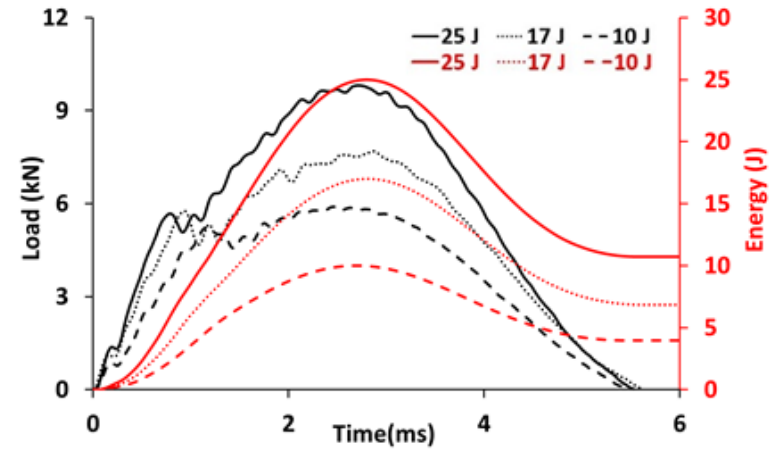

(b)

Fig. 3. Load/energy - time curves of representative (a) P\#1 and (b) P\#2 specimens obtained from drop-weight impact tests.

During the tests, the displacement of the impactor was recorded by the testing machine. The typical load-displacement curves obtained from a series of tests on specimens at different energy levels are shown in Figs. 4a and 4b. Before the initial damage shows as a reduction in the load-displacement curve, an elastic response was exhibited. After damage initiation, damage started to propagate with the increase in load and corresponding displacement. The maximum load was followed by a smooth reduction in both load and displacement during the rebound phase of the impactor. It is noted that in all impacted specimens, the final displacement of the impactor did not return to the origin. This indicated the formation of damage and plastic deformation. 


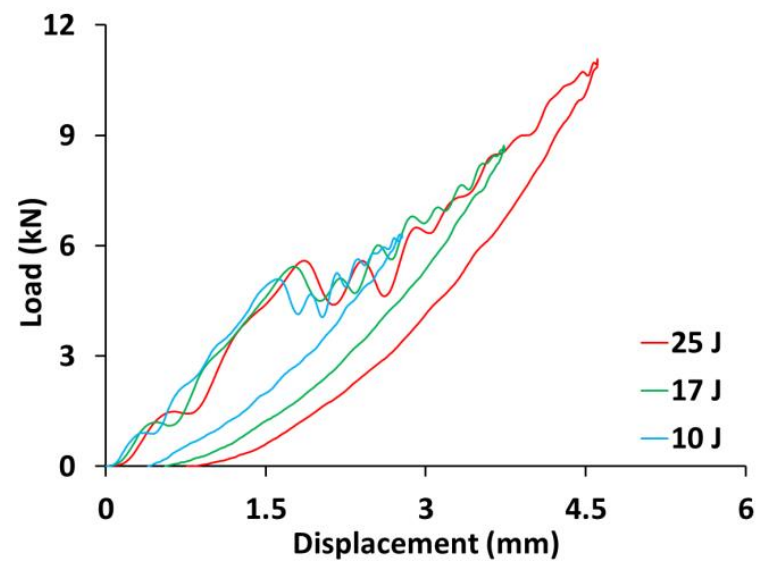

(a)

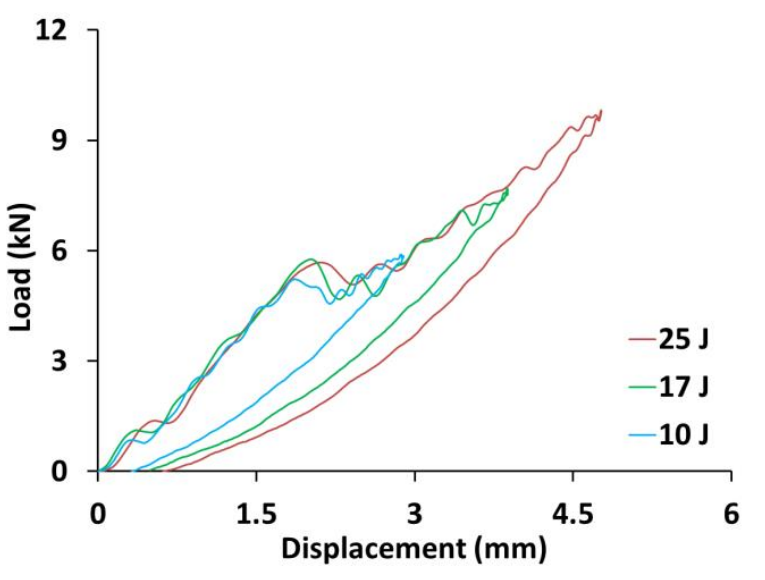

(b)

Fig. 4. Load - displacement curves of (a) P\#1 and (b) P\#2 specimens obtained from drop-weight impact tests.

\subsection{Non-destructive inspection}

Non-destructive inspection plays a crucial role in examining the formation of damage in composite materials [41-43]. A Cscan system was used to obtain the damage maps (Fig. 5) for a selection of specimens, impacted at different energies. Time-of-flight information shows these damage maps as a function of depth through the thickness where red is at the top surface (impacted) and blue is the back of the specimen. A summary of measured experimental data including average indentation, maximum length, maximum width and area of damage footprints obtained from P\#1 and P\#2 specimens, for different impact energy cases, is given in Table 4. 


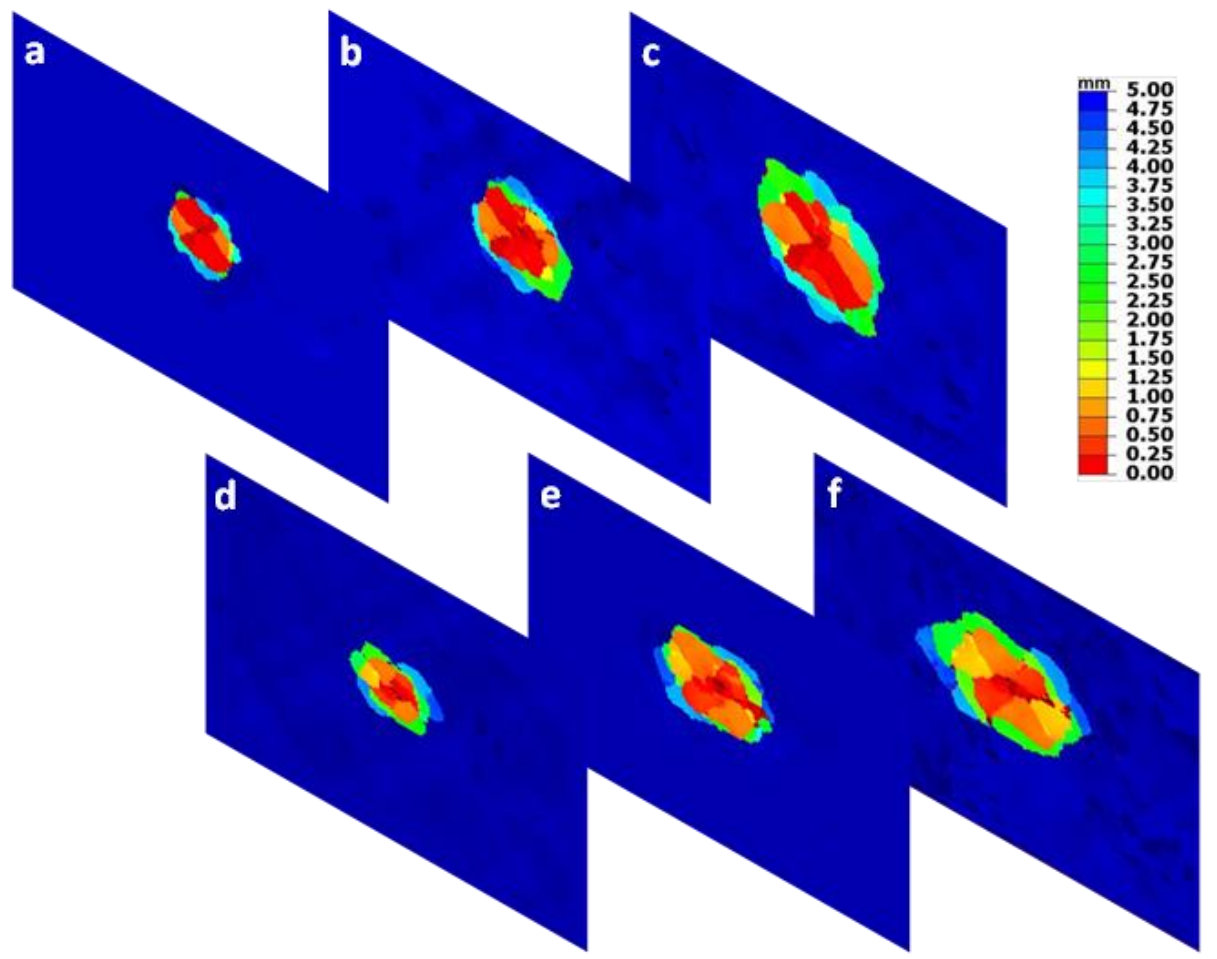

Fig. 5. Damage maps for (a) P\#1-10J (b) P\#1-17J (c) P\#1-25J (d) P\#2-10J (e) P\#2-17J and (f) P\#2-25J drop-weight impact tests.

Table 4

Measurement of damaged area

\begin{tabular}{lllllll}
\hline $\begin{array}{l}\text { Panel } \\
\text { ID }\end{array}$ & $\begin{array}{l}\text { Energy } \\
(\mathrm{J})\end{array}$ & $\begin{array}{l}\text { Number of } \\
\text { samples }\end{array}$ & $\begin{array}{l}\text { Average indentation } \\
\text { depth }(\mathrm{mm})\end{array}$ & $\begin{array}{l}\text { Maximum length } \\
\text { (longitudinal) }(\mathrm{mm})\end{array}$ & $\begin{array}{l}\text { Maximum width } \\
\text { (transverse) }(\mathrm{mm})\end{array}$ & $\begin{array}{l}\text { Delamination } \\
\text { area }\left(\mathrm{mm}^{2}\right)\end{array}$ \\
\hline & 25 & 3 & $0.218 \pm 10.1 \%$ & $51.44 \pm 4.16 \%$ & $50.76 \pm 4.64 \%$ & $1904.7 \pm 2.73 \%$ \\
$\mathrm{P \# 1}$ & 17 & 3 & $0.136 \pm 16.2 \%$ & $41.82 \pm 6.15 \%$ & $37.46 \pm 18.29 \%$ & $1171.3 \pm 5.78 \%$ \\
& 10 & 3 & $0.075 \pm 6.7 \%$ & $29.11 \pm 10.15 \%$ & $28 \pm 7.61 \%$ & $625.6 \pm 10.59 \%$ \\
& 25 & 3 & $0.185 \pm 18.9 \%$ & $65.09 \pm 7.08 \%$ & $36.92 \pm 5.36 \%$ & $1831.7 \pm 5.21 \%$ \\
$\mathrm{P \# 2}$ & 17 & 3 & $0.17 \pm 23.5 \%$ & $45.06 \pm 4.97 \%$ & $28.82 \pm 5.64 \%$ & $1112.3 \pm 3.25 \%$ \\
& 10 & 3 & $0.133 \pm 17.3 \%$ & $33.77 \pm 7.21 \%$ & $21.73 \pm 11.19 \%$ & $610.4 \pm 6.16 \%$ \\
\end{tabular}

4.3 Visual and optical microscopy inspection

4.3.1 Visual inspection 
Following testing, a visual inspection was performed on the impacted specimens. Different indentations and depths were measured using a profilometer for different impact energy levels and these are listed in Table 4. A typical indentation from a $25 \mathrm{~J}$ impact is shown in Fig. $6 \mathrm{a}$.

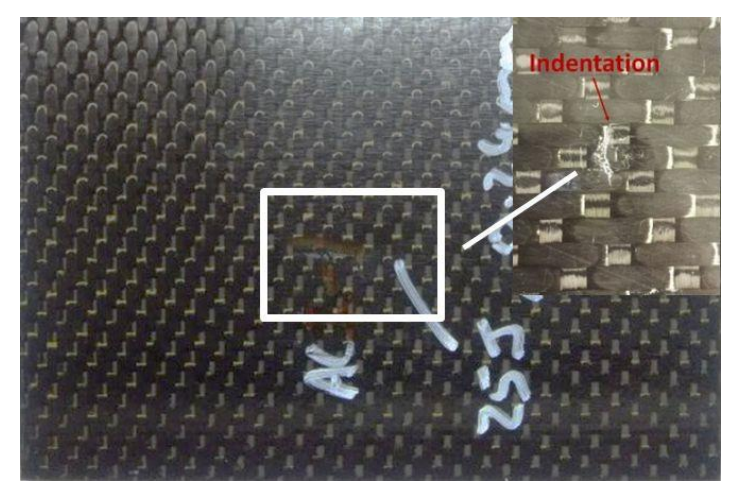

(a)

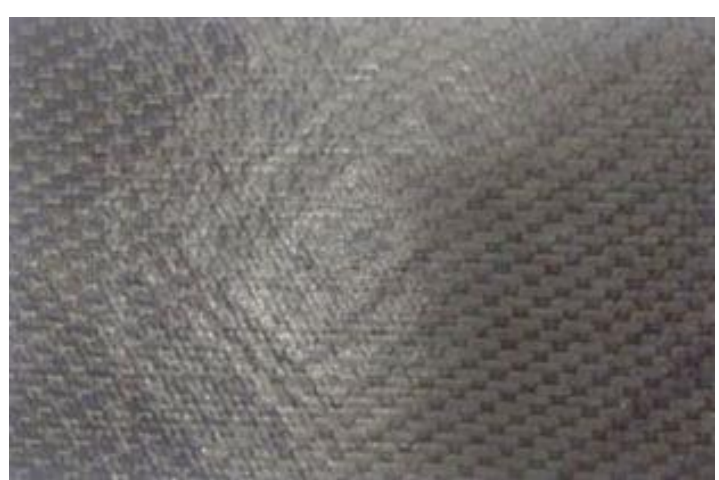

(b)

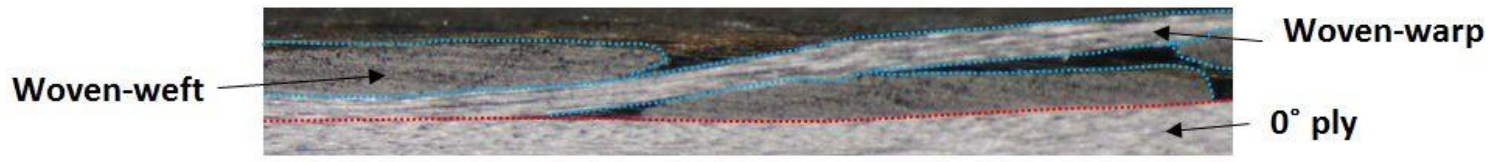

(c)

Fig. 6. Photographs of (a) top surface (impacted) and (b) bottom surface obtained from a P\#1 specimen tested at $25 \mathrm{~J}$ impact energy and (c) cross-section of woven carbon-fibre reinforced lamina.

As shown in Figs. $6 a$ and 6b, there were no visible cracks on the top (impacted) or bottom surface of the tested specimens but all specimens exhibited some level of indentation on the top (impacted) surface. This is consistent with the crackconstraining effects of the woven architecture of the top and bottom plies. Fig. $6 \mathrm{c}$ shows the cross-section of the woven lamina on the top surface of the composite laminates.

\subsubsection{Optical microscopy}

Samples sectioned parallel to the $0^{\circ}$ ply orientation were extracted from P\#1 and P\#2 specimens impacted with 25J impact energy. Fig. 7a shows the sectioning of the post-impacted specimens. The micrographs are shown in Figs. $7 \mathrm{~b}-\mathrm{d}$. 


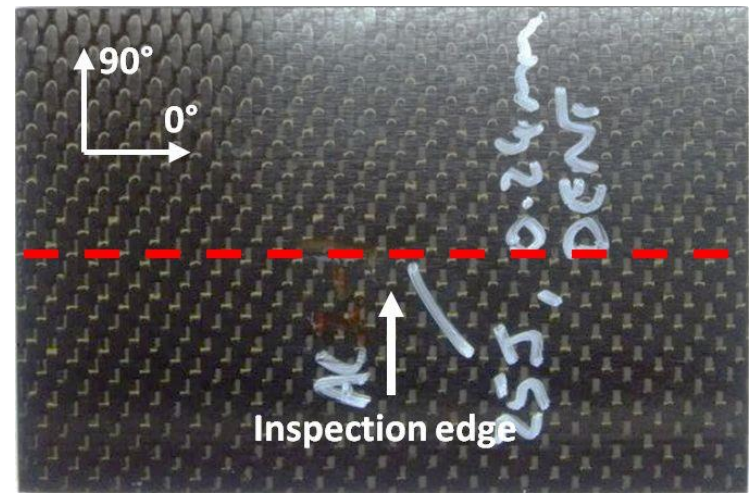

(a)

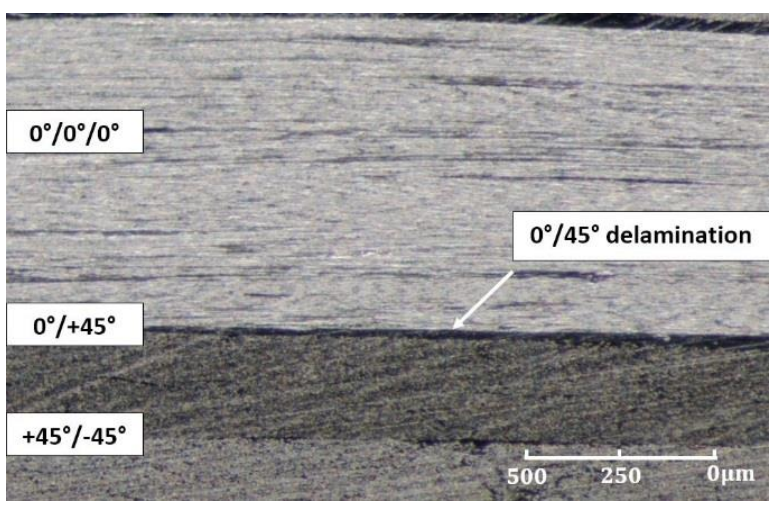

(c)

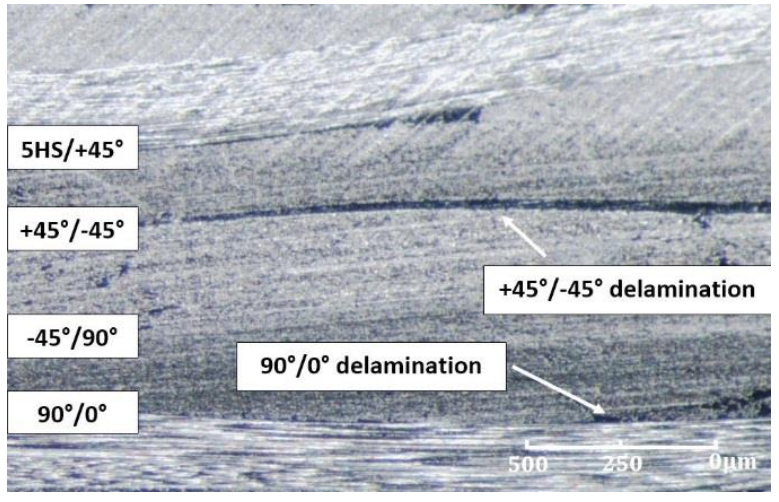

(b)

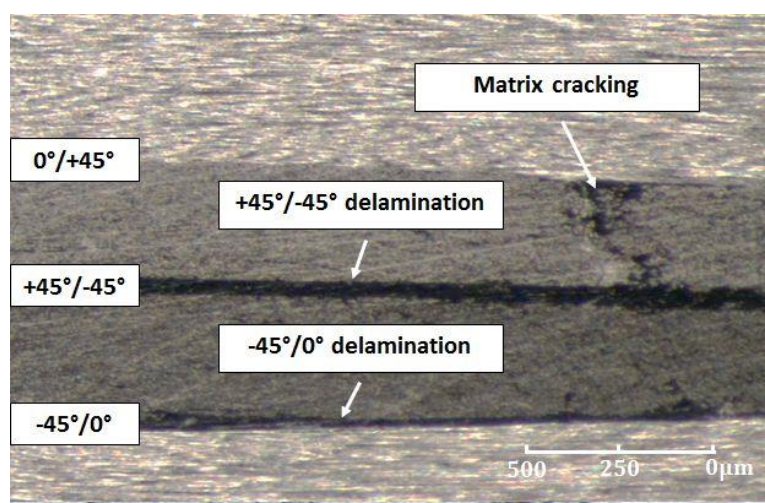

(d)

Fig. 7. (a) Sectioning of specimens (red dash line) and delamination located in (b) $+45^{\circ} /-45^{\circ}$ and $90^{\circ} / 0^{\circ}$, (c) $0^{\circ} / 90^{\circ}$ and (d) $45^{\circ} / 0^{\circ}$ interfaces along with matrix cracking.

\subsection{Effects of impact energy}

Fig. 8a shows the point of initial damage load, and maximum load with corresponding contact time. The status of specimens before and after impact is schematically shown in Fig. 8b. Permanent indentation was observed on the impacted panels.

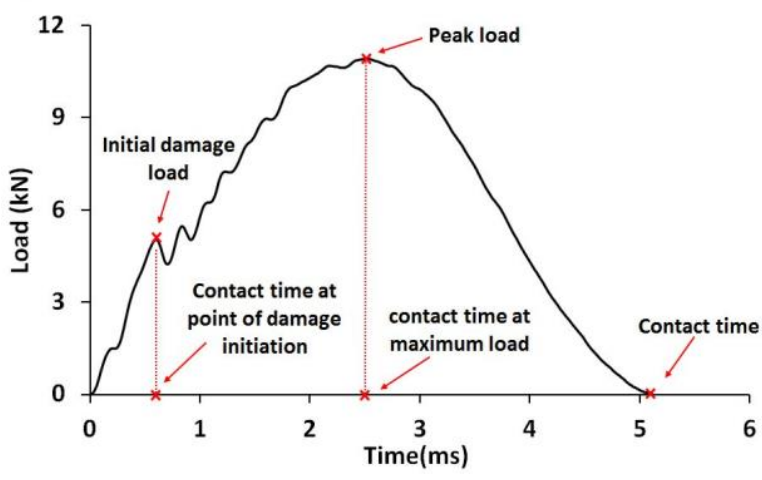

(a)

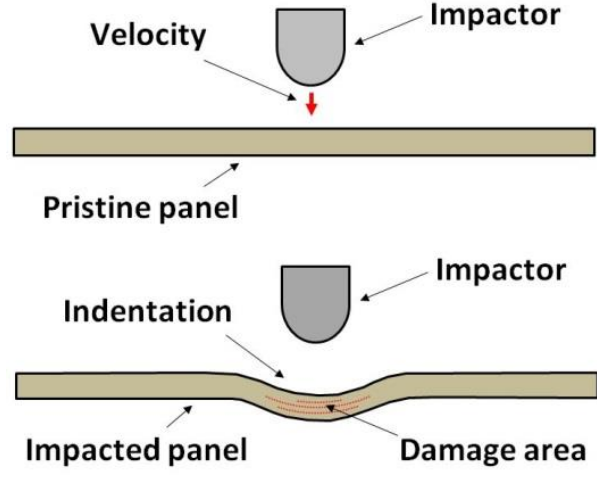

(b) 
Fig. 8. Illustration of primary calculation parameters in (a) typical load-displacement curve and (b) permanent indentation after impact.

As shown in Fig. 9a, the damage area and absorbed energy increased linearly, and at the same rate, with increasing impact energy. The peak load and out-of-plane displacement (indentation depth) also show a linear relationship with impact energy. Increasing impact energy promotes a corresponding increase in peak load and out-of-plane displacement as shown in Figs. $9 \mathrm{~b}$ and $9 \mathrm{c}$. An increase in permanent indentation with measuring impact energy was observed, as shown in Fig. 9c, while the time to the occurrence of initial induced damage exhibited a modest decrease. The impact duration was not significantly affected by the magnitude of the impact energies examined, as shown in Fig. $9 d$.

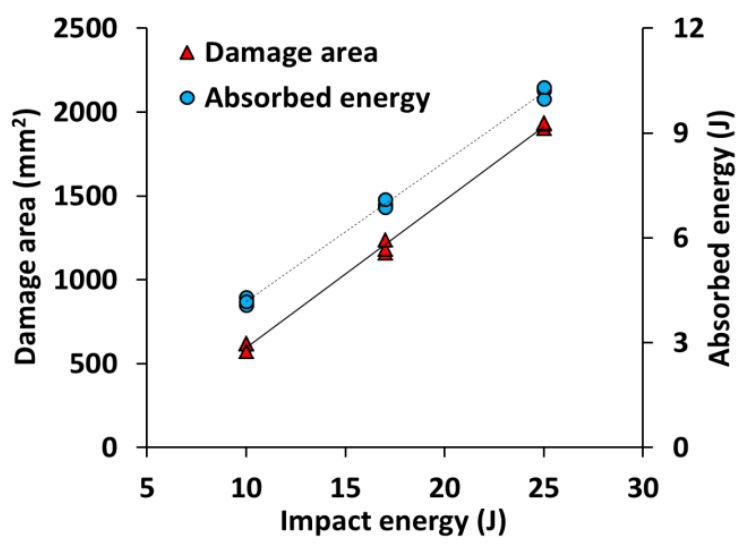

(a)

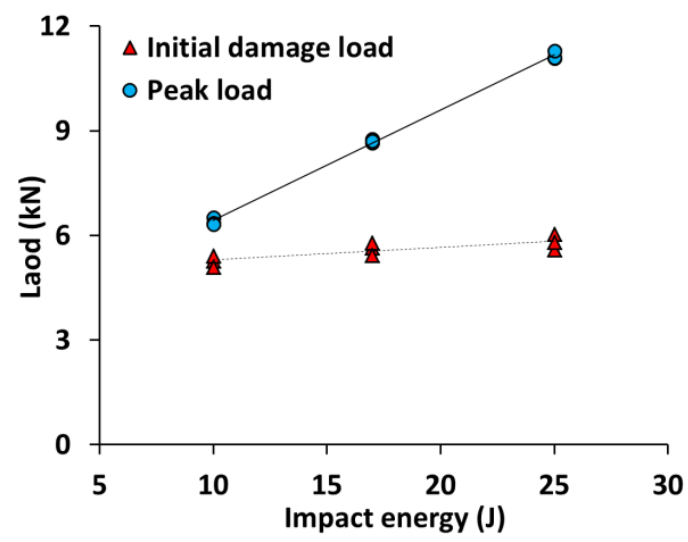

(b)

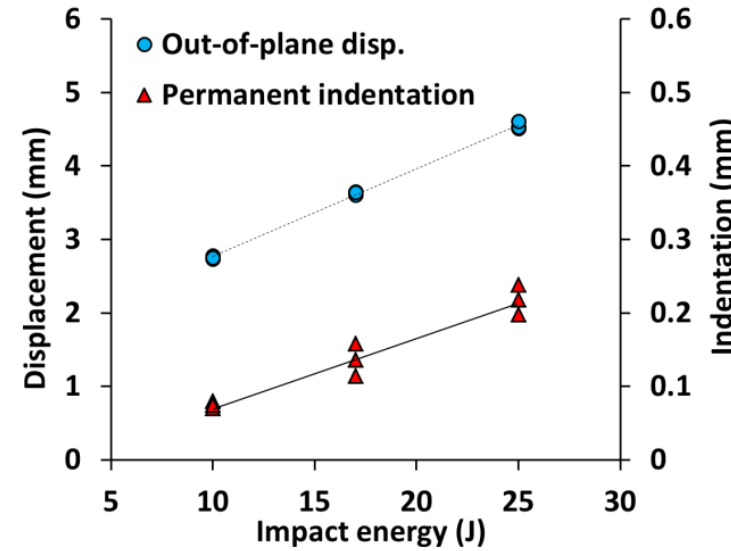

(c)

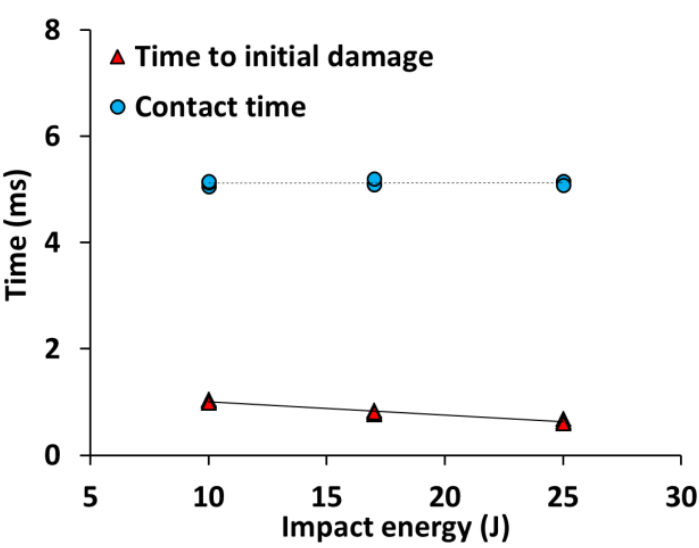

(d)

Fig. 9. (a)Damage area and absorbed energy (b) initial damage load and peak load (c) permanent indentation and outof-plane displacement (d) initial damage time and contact time versus impact energy curves. 
In this work, P\#1 and P\#2 specimens have the same thickness and in-plane dimensions, but different lay-up; the P\#1 lay-up, [5HS/+45/-45/0/90/+45/-45/0/-45/+45/0/-45/+45/90/0/-45/+45/5HS], contains $90^{\circ}$ plies, while P\#2 specimens had the following lay-up: [5HS/0/0/+45/-45/0/0/0/-45/+45/0/0/0/+45/-45/0/0/5HS]. The comparison of load-time curves between P\#1 and P\#2 specimens for 10J, 17J and 25J impact energy are shown in Figs. 10a-c.

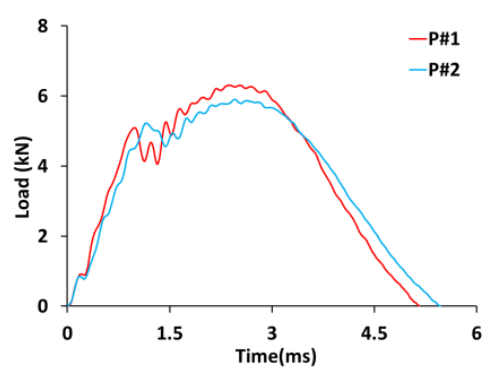

(a)

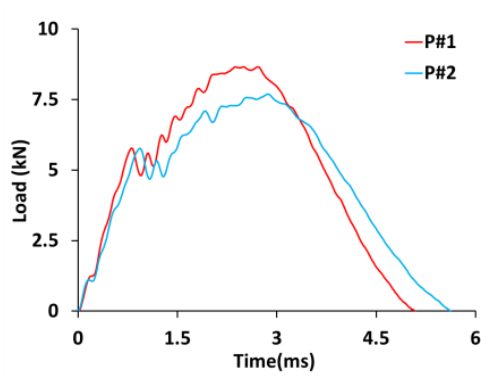

(b)

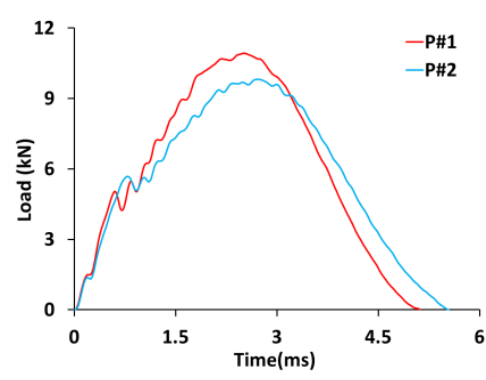

(c)

Fig. 10. Comparison of load-time history obtained from P\#1 and P\#2 specimens for (a) 10J (b) 17J and (c) 25J impact energy cases

The P\#1 specimens delivered a higher peak load than P\#2 specimens for all impact energy levels examined. For instance, in the $25 \mathrm{~J}$ impact energy case shown in Fig. $10 \mathrm{c}$, it is noted that the average peak load of $\mathrm{P \# 1}$ specimens was $11.2 \pm 1.3 \%$ $\mathrm{kN}$ which is $14 \%$ higher than the average peak load, $9.78 \pm 0.34 \% \mathrm{kN}$, for the $\mathrm{P} \# 2$ specimens. The contact time presented by P\#1 and P\#2 specimens is $5.13 \pm 0.6 \% \mathrm{~ms}$ and $5.57 \pm 0.5 \% \mathrm{~ms}$, respectively. These can be explained by the difference in bending stiffness between the P\#1 and P\#2 panels. The bending stiffness matrix $[D]$ for a laminate is given by Eq. (1),

$$
\left[D_{i j}\right]=\frac{1}{3} \sum_{k=1}^{n}\left[\bar{Q}_{i j}\right]_{k}\left(z_{k}^{3}-z_{k-1}^{3}\right)=\sum_{k=1}^{n}\left[\bar{Q}_{i j}\right]_{k}\left(t_{k} \bar{z}_{k}^{2}+\frac{t_{k}^{3}}{12}\right)
$$

where $k$ is the ply number in a lay-up and $n$ is the total number of plies. In this equation, $[\bar{Q}]_{k}$ is the stiffness of the $k^{\text {th }}$ layer, $t_{k}$ is the thickness of the $k^{t h}$ layer, and $\bar{Z}_{k}$ is the distance from the mid-plane of the laminate to the centroid of the $k^{\text {th }}$ layer [44]. 
A measure of the overall bending stiffness of a laminate may be obtained through the trace of the bending stiffness matrix, $\operatorname{Tr}[D]=D_{11}+D_{22}+2 D_{33}[45] . \operatorname{Tr}[D]$ for P\#1 and P\#2 panels were calculated at $1553 \mathrm{~N} \cdot \mathrm{m}$ and $1454 \mathrm{~N} \cdot \mathrm{m}$, respectively. Consequently, the usage of $90^{\circ}$ plies increased the bending stiffness of the P\#1 specimens, which resulted in a higher peak load and shorter contact time between impactor and specimen.

Experimental data obtained from P\#1 and P\#2 specimens are compared in Fig. 11a. The non-destructive inspection results showed that the projected damage area was not affected by the changing of the lay-up, but the damage boundaries were significantly altered, as shown in Fig. $11 \mathrm{~b}$. There are no $90^{\circ}$ plies in the P\#2 specimens, so any propagation of delamination along the $90^{\circ}$ direction was constrained, while delamination was observed to extend along the $0^{\circ}$ direction. Accordingly, the $0^{\circ}$ and $90^{\circ}$ plies in the $\mathrm{P \# 1}$ specimens promoted the growth of delamination along the $0^{\circ}$ and $90^{\circ}$ orientations, respectively [8].

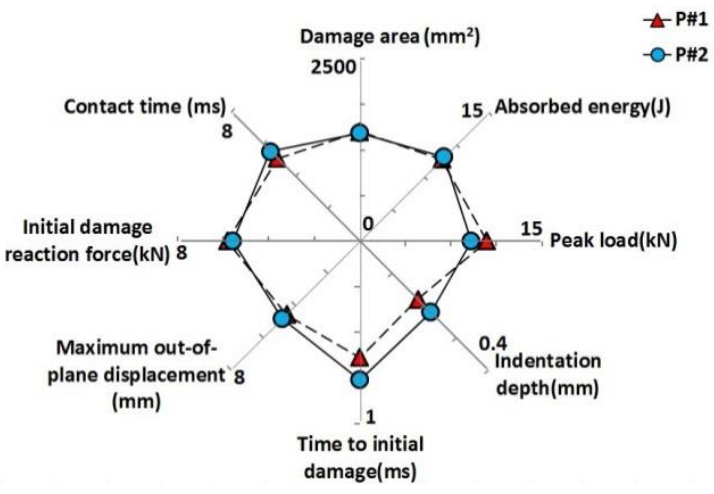

(a)

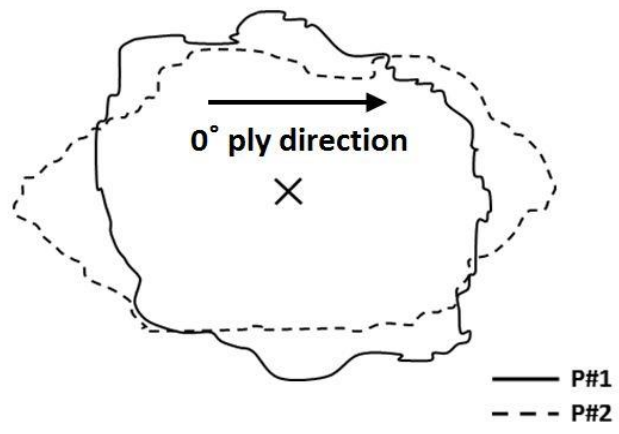

(b)

Fig. 11. Comparison of (a) parameters and (b) projected damage area obtained from P\#1 and P\#2 specimens.

\subsection{Microscopic image analysis}

As shown in the Figs. $7 \mathrm{~b}-\mathrm{d}$, delamination was observed between $0^{\circ} /+45^{\circ}, 0^{\circ} \%+45^{\circ}, 0^{\circ} / 90^{\circ}, 90^{\circ} /+45^{\circ}, 90^{\circ} /-45^{\circ}$ and $+45^{\circ} \%$ $45^{\circ}$ plies, and the cracks tended to propagate along the fibre direction. Matrix cracking was also observed in these crosssections. For all micro examination samples, no delamination was found at the interface between blocked plies (e.g. $0^{\circ} / 0^{\circ} / 0^{\circ}$ ) as shown in Fig. 7c, which was also indicated by non-destructive inspection results. In the damage maps for P\#2, damage along the $0^{\circ}$ direction was attained at a depth of $1 \mathrm{~mm}$, and the second $0^{\circ}$ damage was observed at a depth of $1.75 \mathrm{~mm}$, which indicated there was no damage between blocked $0^{\circ}$ plies $\left(0^{\circ} / 0^{\circ} / 0^{\circ}\right)$ whose thickness covered the depth from $1 \mathrm{~mm}$ and $1.75 \mathrm{~mm}$. This supports the decision of combining contiguous plies, which have the same fibre orientation, into single element thickness in finite-element computational models. 


\section{Modelling the impact behaviour}

\subsection{Overview of damage model}

The failure modes presented by unidirectional and woven composite laminates can be broadly classified into two categories: interlaminar and intralaminar failure as shown in Fig. 12.

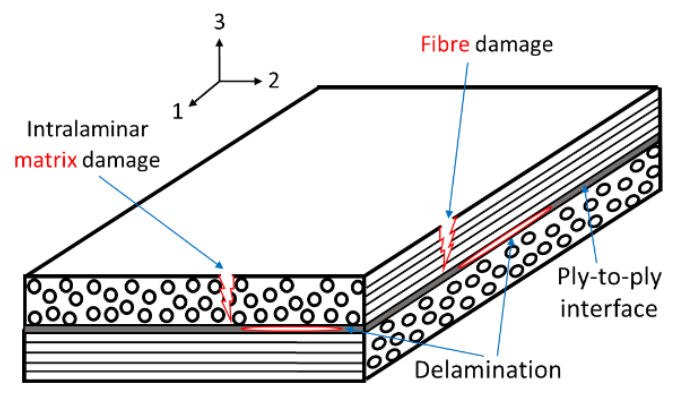

(a)

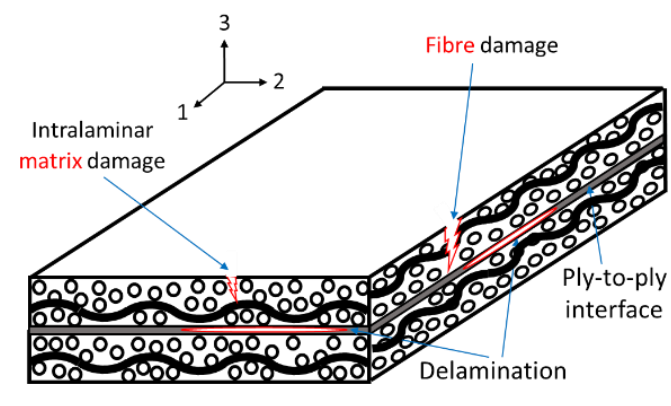

(b)

Fig. 12. Failure modes in (a) unidirectional and (b) woven carbon fibre reinforced composite laminates.

A damage model, based on these failure modes, was developed based on continuum damage mechanics (CDM) principles first proposed by Kachanov [46] and Rabotnov [47]. In the computational model, the full 3D implementation, an improved characteristic length determination, nonlinear shear behaviour [48], load reversal mechanism and a unified matrix damage mechanism $[49,50]$ were integrated into an in-house VUMAT user subroutine for Abaqus/Explicit [28].

\subsubsection{Intralaminar damage model}

As shown in the Fig. 12, for unidirectional carbon fibre reinforced composite lamina, the material response in the longitudinal direction is dominated by fibres. In the transverse and through thickness direction, the material response is dominated by the matrix. In woven carbon fibre reinforced composites, the in-plane material response (along the $0^{\circ}$ and $90^{\circ}$ direction) is dominated by the fibres, and the through thickness material response is dominated by the matrix. Consequently, the presented intralaminar damage model accounts for two main forms of damage: fibre-dominated and matrix-dominated damage. Fibre-dominated damage is characterised by fibre pull-out, fibre-matrix debonding and fibre breakage, and matrixdominated damage is characterised by matrix cracking. 
Fibre-dominated failure modes. A bilinear law was used to model the material response in the fibre direction which is dominated by fibre failure. Damage initiation was determined by comparing the strain to the longitudinal failure initiation strain. Damage initiation criteria for controlling the initiation of damage in the fibre direction, under tensile loading and compressive loading, are shown in Eq. (2) and Eq. (3), respectively,

$$
\begin{aligned}
& F_{f i b}^{T}\left(\varepsilon_{i j}\right)=\left(\frac{\varepsilon_{i j}}{\varepsilon_{i j}^{O T}}\right)^{2} \geq 1, \\
& F_{f i b}^{C}\left(\varepsilon_{i j}\right)=\left(\frac{\varepsilon_{i j}}{\varepsilon_{i j}^{O C}}\right)^{2} \geq 1,
\end{aligned}
$$

where $F_{\text {fib }}^{T}$ and $F_{\text {fib }}^{C}$ are the failure indices of fibre damage for tensile and compressive loading cases, respectively, and the failure initiation strains ( $\varepsilon_{i j}^{O T}$ for tension and $\varepsilon_{i j}^{O C}$ for compression) are determined by the strengths and moduli in the corresponding directions. In this work, the fibre tensile and compressive failure initiation strains for unidirectional IMS60/epoxy were $1.27 \%$ and $0.63 \%$, respectively. For 5HS AS4/epoxy, the fibre tensile and compressive failure initiation strains were $1.32 \%$ and $1.05 \%$, respectively. The subscripts $i j$ indicate the failure direction $\left(i=j=1\right.$ for $0^{\circ}$ direction, $i=$ $j=2$ for $90^{\circ}$ direction). $\varepsilon_{i j}$ is the acting strain in each layer of the composite laminates with respect to the local (material) coordinate system.

The damage is characterised by three monotonically increasing damage variables. The parameter $d_{f i b}^{T}$ refers to tensile damage in the fibre direction, $d_{\text {fib }}^{C}$ refers to compressive damage in the fibre direction, and $d_{\text {mat }}$ refers to matrix cracking due to a combination of transverse tension/compression and shear loading. The damage parameter associated with loading in the longitudinal (fibre-dominated) direction is given in Eq. (4),

$$
d_{f i b}^{T(C)}=\frac{\varepsilon_{f i b}^{F T(C)}}{\varepsilon_{f i b}^{F T(C)}-\varepsilon_{f i b}^{O T(C)}}\left(1-\frac{\varepsilon_{f i b}^{O T(C)}}{\varepsilon_{f i b}^{T(C)}}\right) .
$$

The fibre failure strains, $\varepsilon_{f i b}^{F T(C)}$, are determined by the critical energy release rates $\Gamma_{f i b}^{T(C)}$, and longitudinal tensile/compressive strengths, $X^{T(C)}$, expressed in Eq. (5), 


$$
\varepsilon_{f i b}^{F T(C)}=2 \Gamma_{f i b}^{T(C)} / X^{T(C)} l_{f i b}
$$

where $l_{f i b}$ is the characteristic length associated with the longitudinal direction, and it is determined by $l_{f i b}=V / A$, where $V$ is the element volume and $A$, the fracture plane area, is calculated using an approach proposed in [25].

Matrix-dominated failure modes. Compared to fibre-dominated failure, matrix-dominated failure is, arguably, more complicated, arising from combined transverse tensile, compressive and shear loading cases. The material response along the transverse direction is governed by matrix cracking on a fracture plane, at an angle, $\theta_{f}$, to the fibre direction. Damage initiation and propagation are calculated on the fracture plane as shown in Fig. 13.

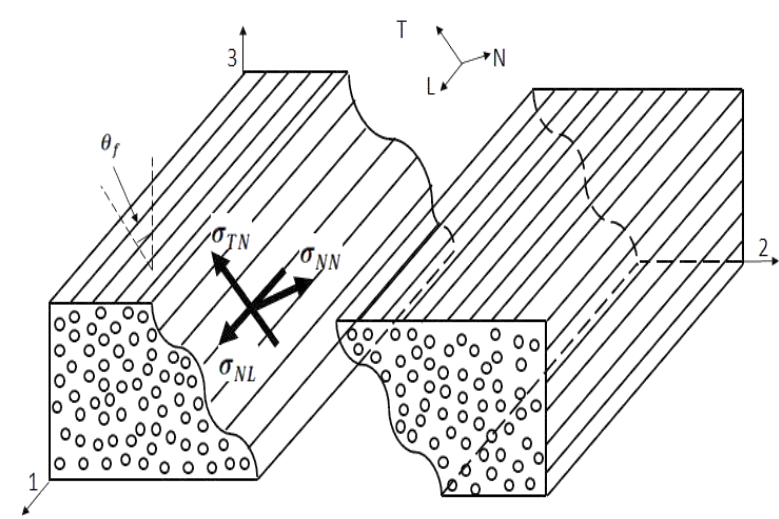

Fig. 13. Material coordinate system $(1,2,3)$ rotated to the fracture plane coordinate system $(L, N, T)$.

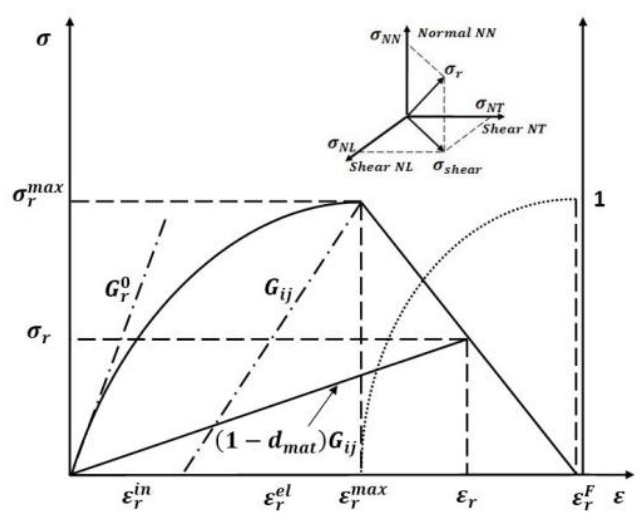

Fig. 14. Mixed-mode intralaminar matrix damage evolution in unidirectional composites.

The matrix damage initiation criterion [51] for unidirectional composites is based on the stress state on the fracture plane which contains a linear normal stress, $\sigma_{N N}$, and nonlinear stresses $\sigma_{L N(N T)}$. The damage initiation criteria for unidirectional composite lamina are shown in Eq. (6) and Eq. (7). The failure indices, $\mathrm{F}_{\text {mat }}^{T}$ and $F_{\text {mat }}^{C}$ are functions of the fracture plane normal stress $\left(\sigma_{N N}\right)$ and in-plane shear stresses ( $\sigma_{L N}$ and $\left.\sigma_{N T}\right)$;

$$
\begin{gathered}
\mathrm{F}_{\text {mat }}^{T}=\left(\frac{\sigma_{N N}}{S_{23}^{A}}\right)^{2}+\left(\frac{\sigma_{N T}}{S_{23}^{A}}\right)^{2}+\left(\frac{\sigma_{L N}}{S_{12}^{A}}\right)^{2}+\lambda\left(\frac{\sigma_{N N}}{S_{23}^{A}}\right)\left(\frac{\sigma_{L N}}{S_{12}^{A}}\right)^{2}+\kappa\left(\frac{\sigma_{N N}}{S_{23}^{A}}\right) \text { for } \sigma_{N N}>0, \\
F_{\text {mat }}^{C}=\left(\frac{\sigma_{N T}}{S_{23}^{A}-\mu_{N T} \sigma_{N N}}\right)^{2}+\left(\frac{\sigma_{L N}}{S_{12}^{A}-\mu_{L N} \sigma_{N N}}\right)^{2} \text { for } \sigma_{N N} \leq 0 .
\end{gathered}
$$


The stress tensor $\sigma_{L N T}=\left[T\left(\theta_{f}\right)\right] \sigma_{123}\left[T\left(\theta_{f}\right)\right]^{T}$ on the fracture plane is rotated using the standard transformation matrix $T\left(\theta_{f}\right)$, from the material coordinate system (123) to the fracture plane coordinate system $(L N T) . \theta_{f}$ is the angle of the potential fracture surface. Parameters $\lambda$ and $\kappa$ are defined by $\lambda=2 \mu_{L N} S_{23}^{A} / S_{12}^{A}-\kappa$, and $\kappa=\left(S_{12}^{A}-\left(Y_{T}\right)^{2}\right) / S_{23}^{A} Y_{T}$ [52], where $S_{12}^{A}$ and $S_{23}^{A}$ are the shear strengths. The transverse friction coefficients, $\mu_{N T}$ and $\mu_{L N}$, are based on MohrCoulomb theory where $\mu_{N T}=-1 / \tan \left(2 \theta_{f}\right), S_{23}^{A}=Y_{C} / 2 \tan \left(\theta_{f}\right)$ and $\mu_{L N}=\mu_{N T} S_{12}^{A} / S_{23}^{A}, Y_{T}$ and $Y_{C}$ are the transverse tensile strength and transverse compressive strength, respectively.

For the woven composite materials, the Hashin-Rotem criteria [53], which consider the interaction between normal stress $\left(\sigma_{33}\right)$ and shear stress $\left(\sigma_{13}\right.$ and $\left.\sigma_{23}\right)$ on the plane perpendicular to the through-thickness direction, were used to govern the intralaminar matrix damage initiation in the through-thickness direction, given by,

$$
\left(\frac{\sigma_{33}}{\sigma_{33}^{O T(C)}}\right)^{2}+\left(\frac{\sigma_{13}}{\sigma_{13}^{O}}\right)^{2}+\left(\frac{\sigma_{23}}{\sigma_{23}^{O}}\right)^{2}-1 \geq 0
$$

where $\sigma_{i j}(i, j=1,2,3)$ are the stresses acting on the fracture surfaces and $\sigma_{i j}^{O T(C)}(i j=1,2,3)$ represent the strengths for tension and compression, respectively. $\sigma_{13}^{O}$ and $\sigma_{23}^{O}$ are the shear strength under corresponding shear loads.

In the unidirectional composite ply, once damage initiates, the stresses acting on the fracture surface described in Puck's criteria were combined as the $l^{2}$-norm,

$$
\sigma_{r}=\sqrt{\left\langle\sigma_{N N}\right\rangle^{2}+\left(\sigma_{L N}\right)^{2}+\left(\sigma_{N T}\right)^{2}}
$$

with the corresponding strain, $\varepsilon_{r}$, acting on the fracture plane, defined as the sum of the $l^{2}$-norms of the corresponding elastic and inelastic strain vectors, given by,

$$
\begin{gathered}
\varepsilon_{r, e l}=\sqrt{\left\langle\varepsilon_{N N}\right\rangle^{2}+\left(\gamma_{L N}^{e l}\right)^{2}+\left(\gamma_{N T}^{e l}\right)^{2}} \\
\varepsilon_{r, i n}=\sqrt{\left(\gamma_{L N}^{i n}\right)^{2}+\left(\gamma_{N T}^{i n}\right)^{2}}
\end{gathered}
$$


Fig. 14 shows the overall damage progression for mixed-mode matrix damage in unidirectional composites. The degradation on the fracture plane was defined using a monotonic damage parameter, $d_{\text {mat }}$, given by,

$$
d_{m a t}=\frac{\varepsilon_{r}^{f}-\varepsilon_{r, i n}^{0}}{\varepsilon_{r}^{f}-\varepsilon_{r}^{0}}\left(1-\frac{\varepsilon_{r}^{0}-\varepsilon_{r}}{\varepsilon_{r}-\varepsilon_{r, i n}^{0}}\right)
$$

where $\varepsilon_{r, i n}^{0}$ is the $l^{2}$-norm of the inelastic strain vector at damage initiation of a unidirectional composite ply. $\varepsilon_{r}^{0}$ and $\varepsilon_{r}^{f}$ are the $l^{2}$-norms of applied strains at initial failure and final failure in a unidirectional composite ply, respectively.

In the unidirectional damage model, the matrix-dominated damage propagation is governed by the critical mixed-mode strain energy release rate, $\Gamma_{r}^{c}$, which is a function of the stresses acting on the fracture surface $\left(\sigma_{N N}^{0}, \sigma_{L N}^{0}, \sigma_{N T}^{0}\right)$ and their $l^{2}$-norm $\left(\sigma_{r}^{0}\right)$, and the corresponding critical strain energy release rates $\left(\Gamma_{22}^{c}, \Gamma_{12}^{c}, \Gamma_{23}^{c}\right)$. The critical mixed-mode strain energy release rate, $\Gamma_{r}^{c}$, is given by,

$$
\Gamma_{r}^{C}=\Gamma_{22}^{C}\left(\frac{\sigma_{N N}^{0}}{\sigma_{r}^{0}}\right)^{2}+\Gamma_{12}^{C}\left(\frac{\sigma_{L N}^{0}}{\sigma_{r}^{0}}\right)^{2}+\Gamma_{23}^{C}\left(\frac{\sigma_{N T}^{0}}{\sigma_{r}^{0}}\right)^{2}
$$

For the matrix-dominated damage propagation in a woven composite ply, the stresses $\left(\sigma_{33}, \sigma_{13}\right.$ and $\left.\sigma_{23}\right)$ acting on the plane perpendicular to the thorough-thickness direction were combined as the $l^{2}$-norm,

$$
\sigma_{3}=\sqrt{\left(\sigma_{33}\right)^{2}+\left(\sigma_{13}\right)^{2}+\left(\sigma_{23}\right)^{2}}
$$

The degradation of the combined stresses on the plane perpendicular to the thorough-thickness direction was defined using the corresponding damage parameter, $d_{3}$, given by,

$$
d_{3}=\frac{\varepsilon_{3}^{f}-\varepsilon_{3, \text { in }}^{0}}{\varepsilon_{3}^{f}-\varepsilon_{3}^{0}}\left(1-\frac{\varepsilon_{3}^{0}-\varepsilon_{3}}{\varepsilon_{3}-\varepsilon_{3, \text { in }}^{0}}\right),
$$

where $\varepsilon_{r, \text { in }}^{0}$ is the $l^{2}$-norm of the inelastic strain vector at damage initiation. $\varepsilon_{r}^{0}$ and $\varepsilon_{r}^{f}$ are the $l^{2}$-norms of applied strains at initial failure and final failure, respectively. $\varepsilon_{3}$ is the sum of the elastic and inelastic strain components, given by, 


$$
\begin{gathered}
\varepsilon_{3, e l}=\sqrt{\left(\varepsilon_{33}\right)^{2}+\left(\gamma_{13}^{e l}\right)^{2}+\left(\gamma_{23}^{e l}\right)^{2}}, \\
\varepsilon_{3, i n}=\sqrt{\left(\gamma_{13}^{i n}\right)^{2}+\left(\gamma_{23}^{i n}\right)^{2}} .
\end{gathered}
$$

In the woven damage model, the critical mixed-mode strain energy release rate $\left(\Gamma_{3}^{c}\right)$ for governing the matrix-dominated damage propagation is related to the stresses acting on a plane perpendicular to the through-thickness direction in the material coordinate system $\left(\sigma_{33}^{0}, \sigma_{13}^{0}, \sigma_{23}^{0}\right)$, their $l^{2}$-norm $\left(\sigma_{3}^{0}\right)$, and the corresponding critical strain energy release rates $\left(\Gamma_{33}^{c}, \Gamma_{13}^{c}, \Gamma_{23}^{c}\right)$

$$
\Gamma_{3}^{C}=\Gamma_{33}^{C}\left(\frac{\sigma_{33}^{0}}{\sigma_{3}^{0}}\right)^{2}+\Gamma_{12}^{C}\left(\frac{\sigma_{13}^{0}}{\sigma_{3}^{0}}\right)^{2}+\Gamma_{23}^{C}\left(\frac{\sigma_{23}^{0}}{\sigma_{3}^{0}}\right)^{2}
$$

In this damage model, experimental data obtained from standard V-notch Rail Shear (VRS) tests was used to determine the coefficients in Eq. (19) defining the material's nonlinear shear response,

$$
\tau\left(\gamma_{i j}\right)=c_{1}\left[\exp \left(c_{2} \gamma_{i j}\right)-\exp \left(c_{3} \gamma_{i j}\right)\right]
$$

where $c_{i}(i=1,2,3)$ are curve fitting coefficients, and $\gamma_{i j}(i, j=n, s, t, i \neq j)$ are the shear strains.

Prior to damage initiation, shear loading and unloading occurs along gradients defined by the initial shear modulus $G_{i j}$. A representative nonlinear shear stress profile for unidirectional matrix is shown in Fig. 15.
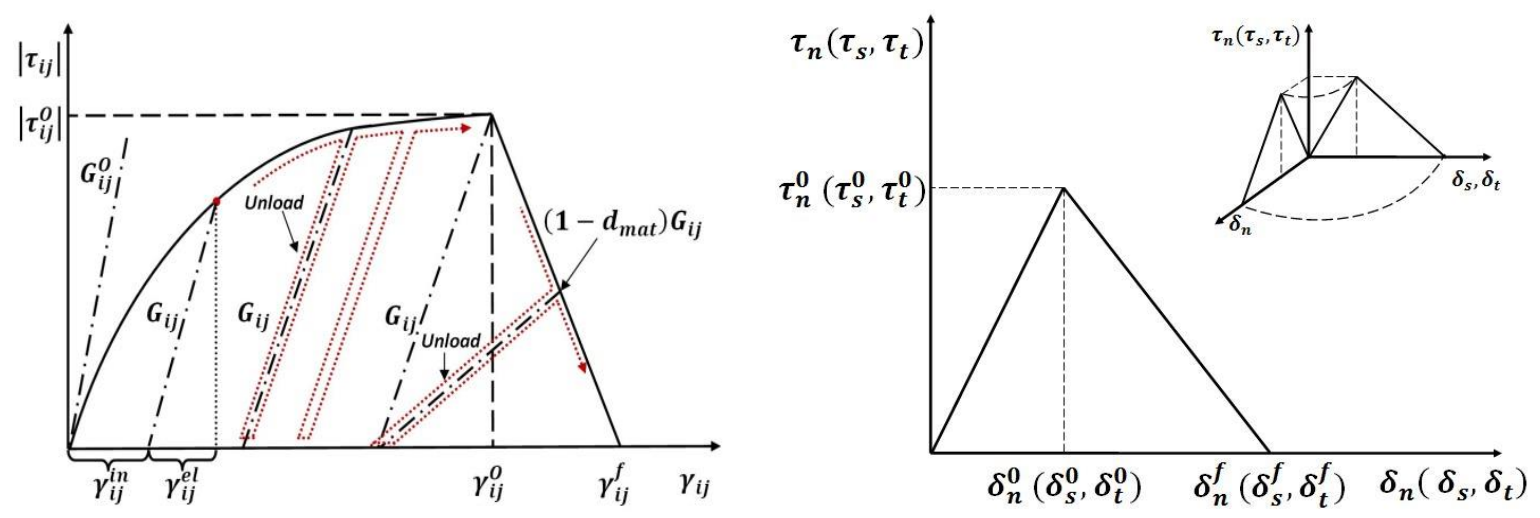
Fig. 15. Non-linear shear profile with different loading/unloading paths.
Fig. 16. Traction-separation response for surface-based interlaminar model.

\subsubsection{Interlaminar damage model}

The built-in surface-based cohesive behaviour in Abaqus/Explicit was used to capture the delamination in composite structures using a bilinear traction-separation relationship as shown in Fig. 16. The interlaminar failure initiation is governed by a quadratic stress criterion, given by,

$$
\left(\frac{\tau_{s}}{\tau_{s}^{0}}\right)^{2}+\left(\frac{\tau_{t}}{\tau_{t}^{0}}\right)^{2}+\left(\frac{\left\langle\tau_{n}\right\rangle}{\tau_{n}^{0}}\right)^{2} \leq 1
$$

where $\tau_{i}(i=n, s, t)$ is the normal direction and in-plane stresses respectively, and $\tau_{i}^{0}(i=n, s, t)$ are the corresponding maximum stresses in each direction. In this model, the Benzeggagh-Kenane (B-K) propagation criterion [54], Eq. (21), was used to propagate the delamination,

$$
G_{c}=G_{I C}+\left(G_{I I C}-G_{I C}\right) B^{\eta}
$$

where $G_{c}$ is the mixed-mode fracture toughness, and $B$ is the local mixed-mode ratio defined as $B=G_{I I} / G_{I}+G_{I I}$. The parameter $\eta$ is the mixed-mode interaction coefficient determined from in-house experiments based on the ASTM D6671/D6671M-03 testing standard [55].

The interface between two plies was represented using the penalty contact algorithm with a measured friction coefficient of 0.25 defined for all ply-to-ply contacts [48]. In order to verify the implementation of the surface-based cohesive behaviour, the Double-Cantilever-Beam (DCB), Four-point End-Notched-Flexure (4ENF) and Mixed-Mode-Beam (MMB) tests were successfully simulated.

The approach reported in $[25,56,57]$ was employed to determine the proper element size and cohesive strength for the interlaminar damage model. Consequently, $1.5 \mathrm{~mm} \times 1.5 \mathrm{~mm}$ single-ply-thickness elements were selected for the model verification. A penalty interface stiffness was determined according to the equation, $k=\alpha E_{22} / t_{p}$, reported in [57], where $\alpha$ is a coefficient set at $50, E_{22}$ is the transverse Young's modulus of the composite and $t_{p}$ is the thickness of an adjacent 
double-ply ( $0.54 \mathrm{~mm}$ for unidirectional ply and $0.7 \mathrm{~mm}$ for woven ply). Generally, the matrix tensile strength was selected as the cohesive tensile strength, which requires a very small element size. To avoid using a very fine mesh, Turon et al. [56] proposed the use of a lower interface strength with a coarser mesh size, which can still accurately capture the softening behaviour ahead of the crack tip. In this context, a nominal normal cohesive strength, $\sigma_{I}=17 \mathrm{MPa}$ for a unidirectional ply and $\sigma_{I}=20 \mathrm{MPa}$ for a woven ply, were able to yield good agreement with experimental results obtained from Mode I tests. The nominal shear cohesive strength, $\sigma_{I I}$, can be determined through,

$$
\sigma_{I I}=\sigma_{I} \sqrt{\frac{G_{I I c}}{G_{I c}}}
$$

where $G_{I C}$ and $G_{I I c}$ are the interlaminar Mode I and Mode II critical energy release rates, respectively. The determined cohesive stiffness and cohesive strength for a unidirectional interface and a woven interface are shown in Table 5.

The comparison of analytical, experimental and computational results obtained from DCB and 4ENF tests showed good correlation as shown in Figs 17a and 17b. In addition, the measured parameter $\eta$ for the B-K propagation criterion was used in the mixed-mode finite element model, with a mode mixity of $88 \%$ ratio and results are shown in Fig. $17 \mathrm{c}$.
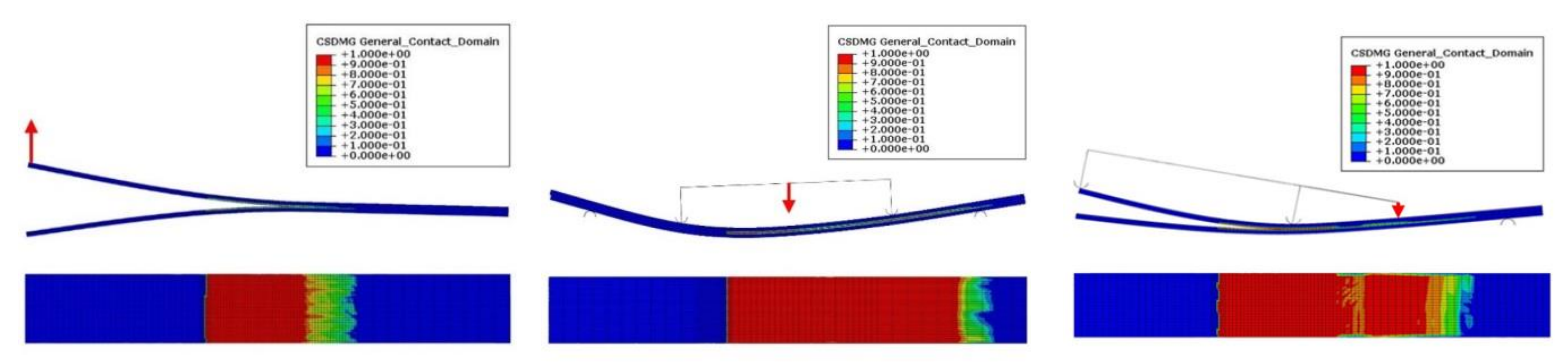

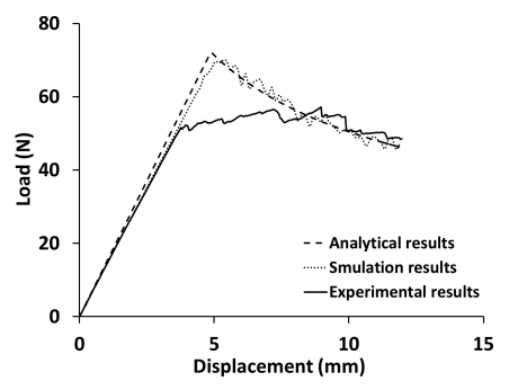

(a)

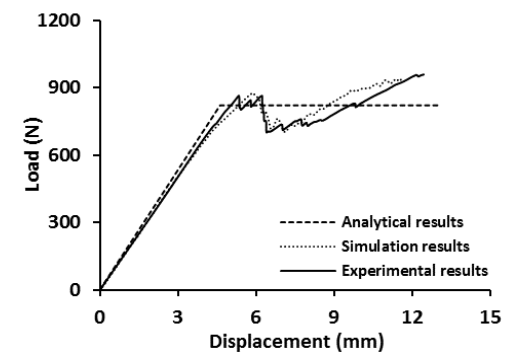

(b)

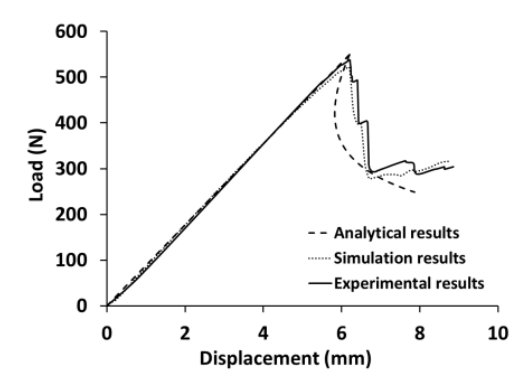

(c)

Fig. 17. Local -displacement curves for (a) DCB test (b) 4ENF test and (c) MMB test. 
An in-house VUMAT subroutine was developed for Abaqus/Explicit to predict the material response of composite structures subjected to low velocity impact. The overall subroutine flowchart is shown in Fig. 18a, and the highlighted matrix-dominated failure subroutine and nonlinear shear behaviour subroutine are shown in Figs. 18b and 18c, respectively.

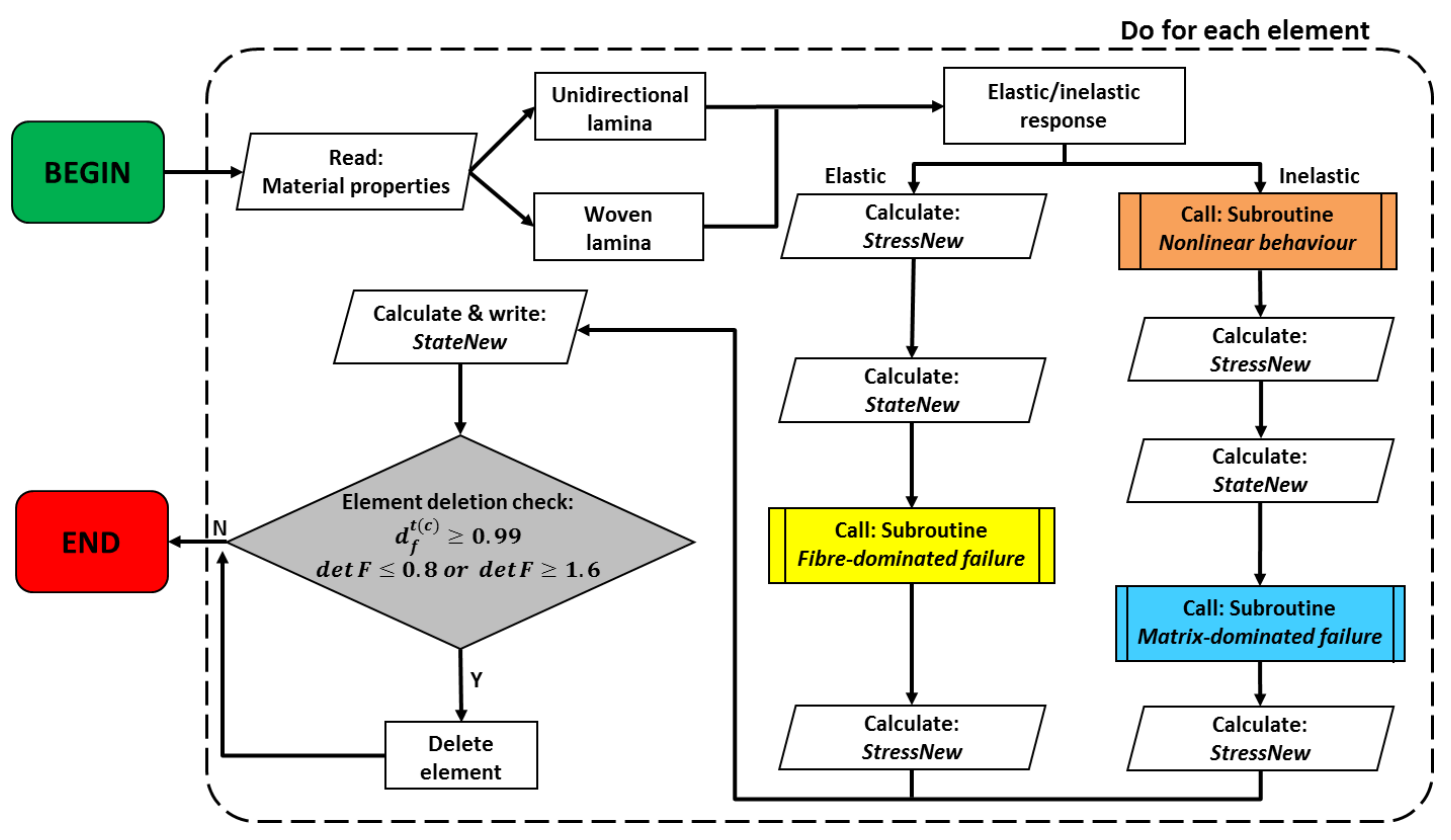

(a)
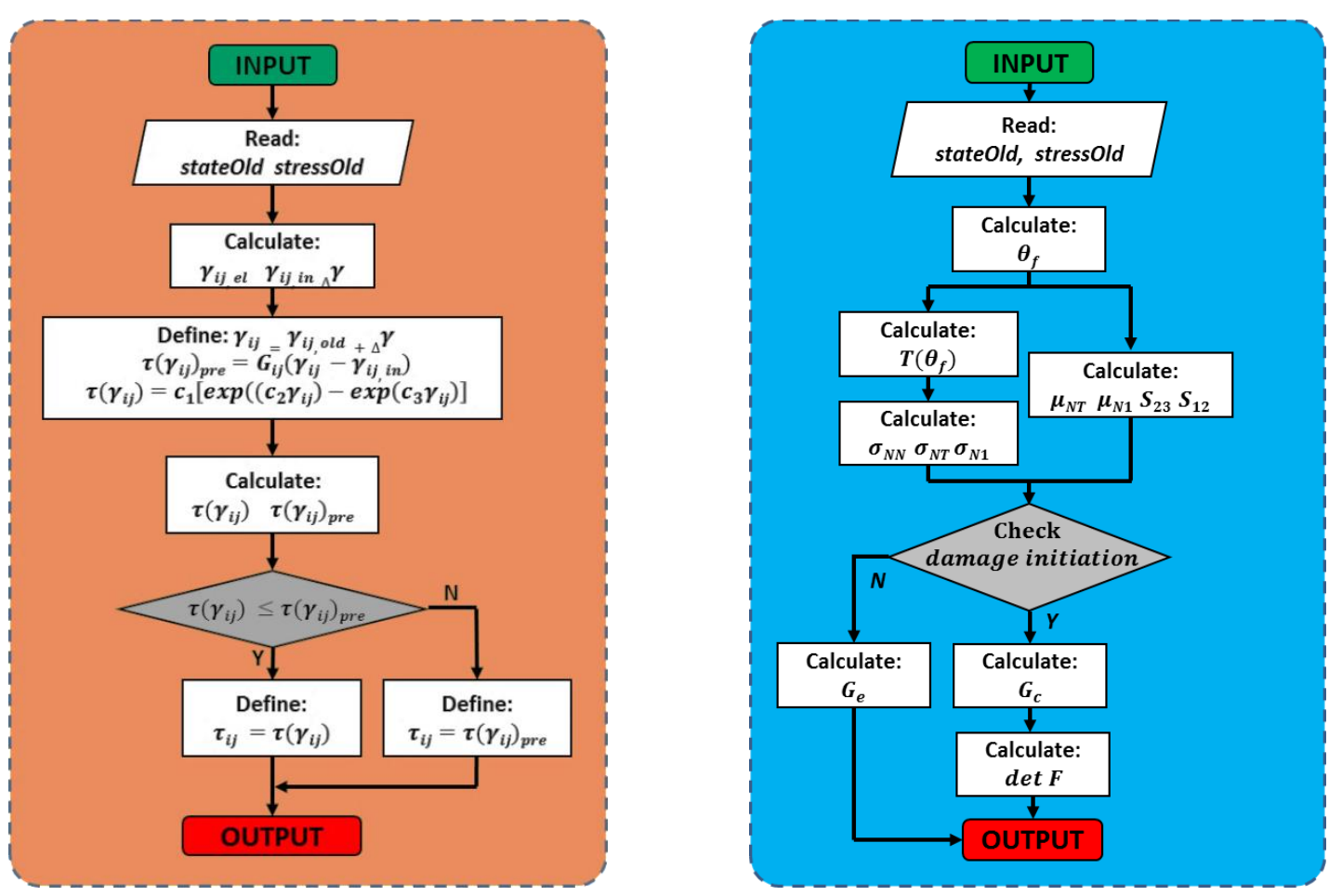
Fig. 18. Flowchart of (a) main subroutine, and highlighted (b) nonlinear shear behaviour and (c) matrix-dominated failure subroutines.

\subsection{Finite element model}

The results obtained from in-house drop-weight impact tests on P\#2 specimens were used to validate the predictive capability of the model for the impact response of composite structures. The impact simulation was carried out in Abaqus 6.11/Explicit, and the virtual test set-up is shown in Fig. 19. The impactor was modelled as a spherically shaped analytical rigid surface, with a reference lumped mass of $6.4 \mathrm{~kg}$. The clamps were defined as rigid bodies and given an initial clamping load on the panel. To suppress spurious energy modes associated with the use of elements with reduced integration, an enhanced stiffness-based hourglass and distortion control were employed. The general contact algorithm available in Abaqus/Explicit was used to simulate contact in the numerical model. For the impactor-ply and clamp-ply contacts, a friction coefficient of 0.2 was used [50].

In this model, the panel was meshed with $1.5 \mathrm{~mm} \times 1.5 \mathrm{~mm}$ single-ply-thickness C3D8R elements with one element through the thickness of each ply. Based on the non-destructive inspection and microscopic examination results, no delamination was found at the interface between blocked plies with the same fibre orientation [8]. It is therefore acceptable to use a single ply to represent the blocked plies with the same fibre orientation, as shown in Fig. 20, to reduce simulation time.

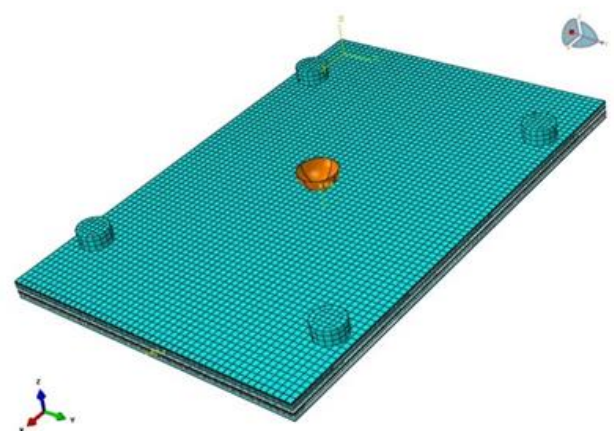

Fig. 19. Finite element model.

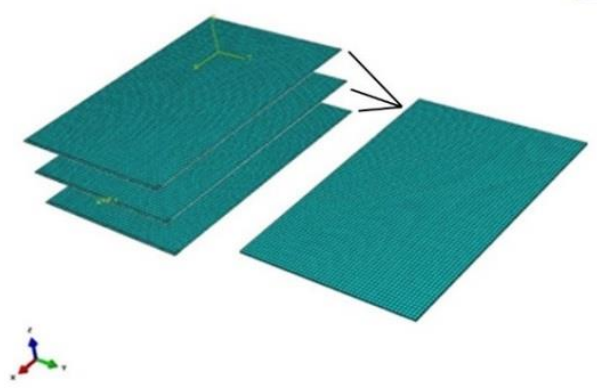

Fig. 20. Combination of 0 degree plies. 
Material properties for IMS60 Carbon-fibre/epoxy and AS4 woven carbon-fibre/epoxy were obtained from a series of material characterisation tests following the test methods reported in [55,58-62]. The interlaminar critical strain energy release rates $\left(G_{I C}\right.$ and $\left.G_{I I C}\right)$, and B-K coefficient $(\eta)$ were determined using standard DCB, 4ENF and MMB tests. The intralaminar critical strain energy release rates associated with fibre-dominated tensile $\left(\left.G_{I c}\right|_{f t}\right)$ and compressive $\left(\left.G_{I c}\right|_{f c}\right)$ failure were measured from Compact Tension (CT) and Compact Compression (CC) testing schemes [26], respectively. The VRS testing method was used to obtain the non-linear shear coefficients, $c_{1}, c_{2}$ and $c_{3}$, required in Eq. (12). The intralaminar critical strain energy release rate associated with matrix-dominated tensile $\left(\left.G_{I c}\right|_{m t}\right)$ failure was assumed to be equivalent to the interlaminar tensile critical strain energy release rate $\left(G_{I C}\right)$. Correspondingly, the intralaminar critical strain energy release rates associated with compressive $\left(\left.G_{I c}\right|_{m c}\right)$ and shear failure $\left(\left.G_{I I c}\right|_{m s}\right)$ were assumed to be equivalent to the interlaminar shear critical strain energy release rate $\left(G_{I I C}\right)[26,50]$. The material properties for numerical simulation are shown in Table 5.

\section{Table 5}

Material properties for IMS60 Carbon-fibre/epoxy and AS4 woven carbon-fibre/epoxy

\begin{tabular}{lll}
\hline Materials & Unidirectional lamina & 5HS lamina \\
\hline Intralaminar critical strain energy & $\left.G_{I c}\right|_{f t}=775 ;\left.G_{I c}\right|_{f c}=87 ;$ & $\left.G_{I c}\right|_{f t}=91 ;\left.G_{I c}\right|_{f c}=42 ;$ \\
release rates $\left(\mathrm{kJ} / \mathrm{m}^{2}\right)$ & $\left.G_{I c}\right|_{m t}=0.46 ;\left.G_{I c}\right|_{f c}=1.51 ;$ & $\left.G_{I c}\right|_{m t}=0.32 ;\left.G_{I c}\right|_{m c}=2.01 ;$ \\
& $\left.G_{I I c}\right|_{m s}=1.51 ;$ & $\left.G_{I I c}\right|_{m s}=2.01 ;$ \\
Non-linear shear properties & $c_{1}=66.5 ; c_{2}=3.2 ; c_{3}=62.4 ;$ & $c_{1}=77.2 ; c_{2}=3.6 ; c_{3}=65.2 ;$ \\
Interlaminar critical strain energy & $G_{I c}=0.46 ; G_{I I c}=1.51 ;$ & $G_{I c}=0.32 ; G_{I I c}=2.01 ;$ \\
release rates $\left(\mathrm{kJ} / \mathrm{m}^{2}\right)$ & & \\
B-K coefficient & $\eta=1.89 ;$ & $\eta=2.09 ;$ \\
Cohesive stiffness $\left(\mathrm{N} / \mathrm{mm}^{3}\right)$ & $8.1 \times 10^{5} ;$ & $6.2 \times 10^{5} ;$ \\
Nominal cohesive strength $(\mathrm{MPa})$ & $\sigma_{I}=17 ; \sigma_{I I}=30 ;$ & $\sigma_{I}=20 ; \sigma_{I I}=34 ;$ \\
\hline
\end{tabular}

\section{Modelling results and discussion}

6.1 Visible damage 
The delamination evolution in the composite laminates, under impact loading, obtained from the numerical analysis is shown in Fig. 21a. The damage variable (CSDMG) associated with surface-based cohesive behaviour was used to evaluate the delamination at each interface defined in the Finite Element (FE) model [28]. Fig. 21b shows the indentation of a postimpacted P\#2 specimen tested at $25 \mathrm{~J}$ impact energy. As shown in Fig. 21c, the permanent indentation was reproduced in the virtual impact test and matched very well with the physical permanent indentation. Fig. 21d shows the side view of the post-impacted panel in the FE simulation.

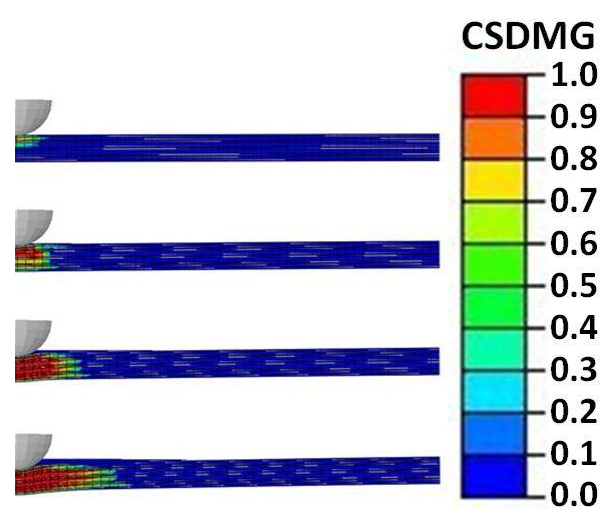

(a)

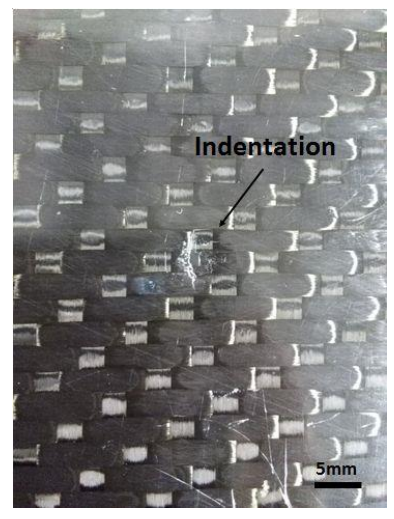

(b)

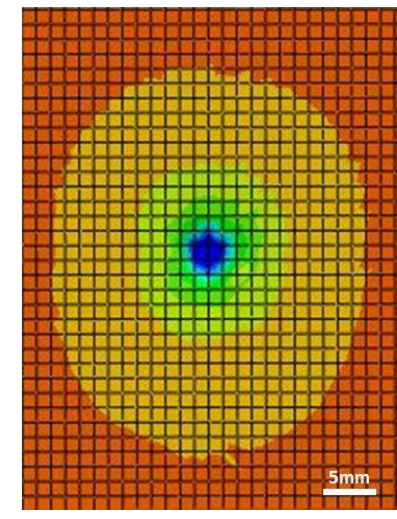

(c)

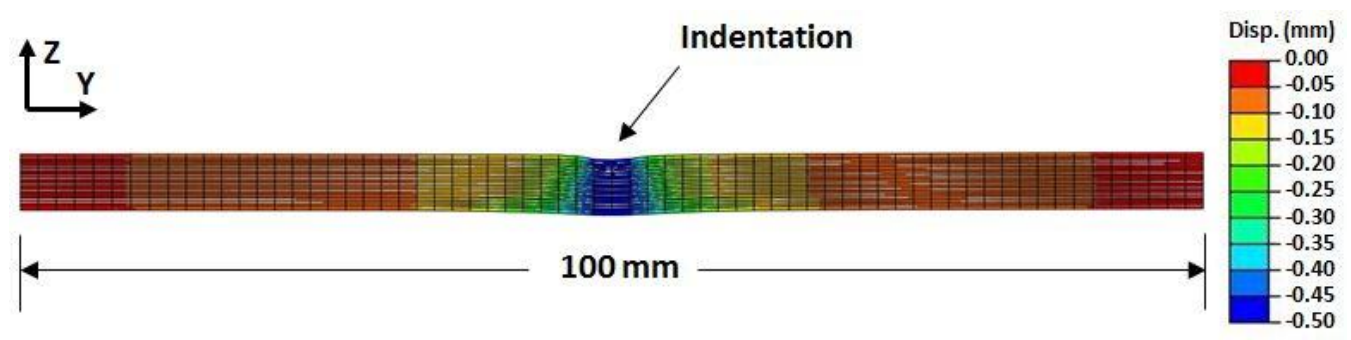

(d)

Fig. 21. (a) Delamination evolution (b) photographic image of the indentation (c) top view and (d) side view of the indentation captured by the damage model for the $25 \mathrm{~J}$ impact energy case.

\subsection{Global impact response}

The load versus time curves obtained from P\#2 specimens for different impact energy cases are shown in Figs. 22a-c. Initial damage, prior to peak load, was evident by a slight dip in load. This was followed by a damage propagation process which stopped at the peak load point. Beyond peak load, a smooth rebounding process is presented by the load versus time curves. As shown in these figures, the material response including peak load, damage propagation and rebounding procedure, presented by the physical impact tests, was accurately captured by the finite element model. The load versus 
impactor displacement curves obtained from P\#2 specimens, for different impact energy cases, are shown in Figs. 22d-f. As shown in these figures, the peak load, maximum displacement of impactor and rebounding behaviour delivered by the predictive model correlated well with experimental results.

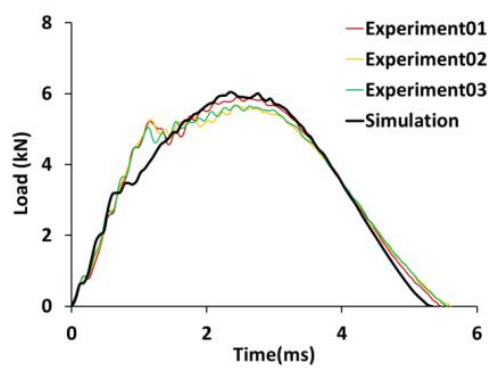

(a)

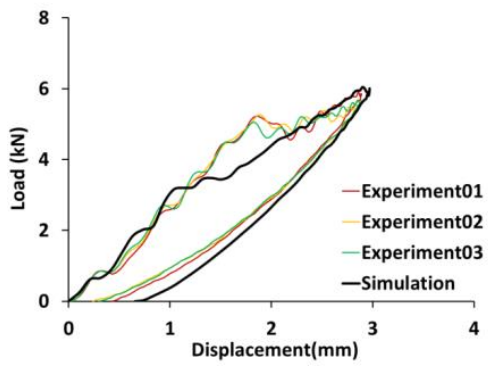

(d)

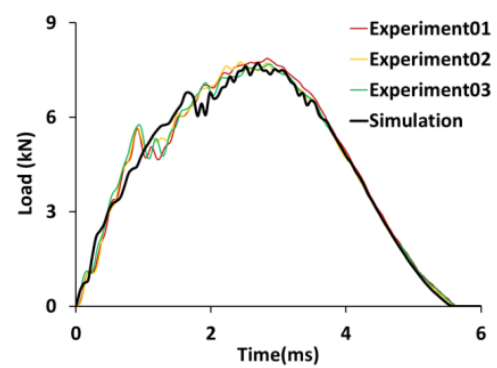

(b)

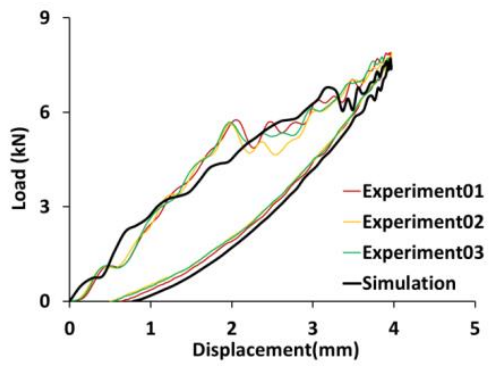

(e)

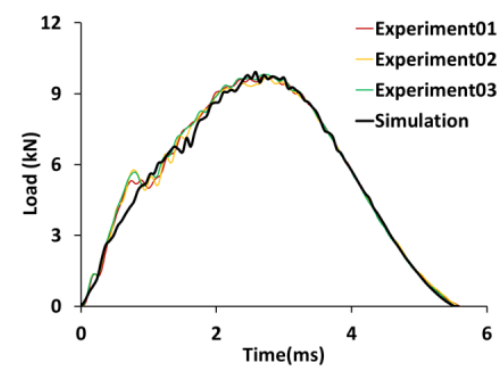

(c)

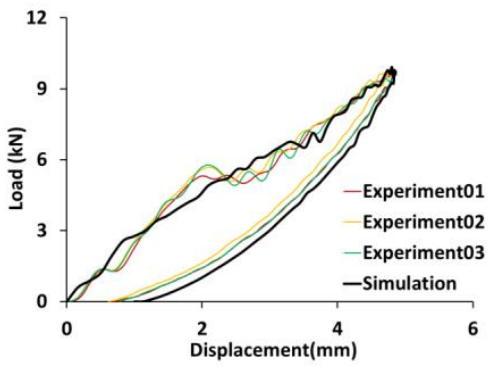

(f)

Fig. 22. Load versus time curves for (a) $10 \mathrm{~J}$, (b) $17 \mathrm{~J}$, (c) $25 \mathrm{~J}$, and load versus impactor displacement curves for (d) 10 $\mathrm{J}$, (e) $17 \mathrm{~J}$, (f) $25 \mathrm{~J}$ impact energy cases obtained from P\#2 specimens.

The absorbed energy versus time curves obtained from P\#2 specimens at different impact energy levels are shown in Fig.

23a. The overall energy dissipation mechanism of P\#2 specimens in the physical and virtual low velocity impact event is exhibited in Fig. 23b.
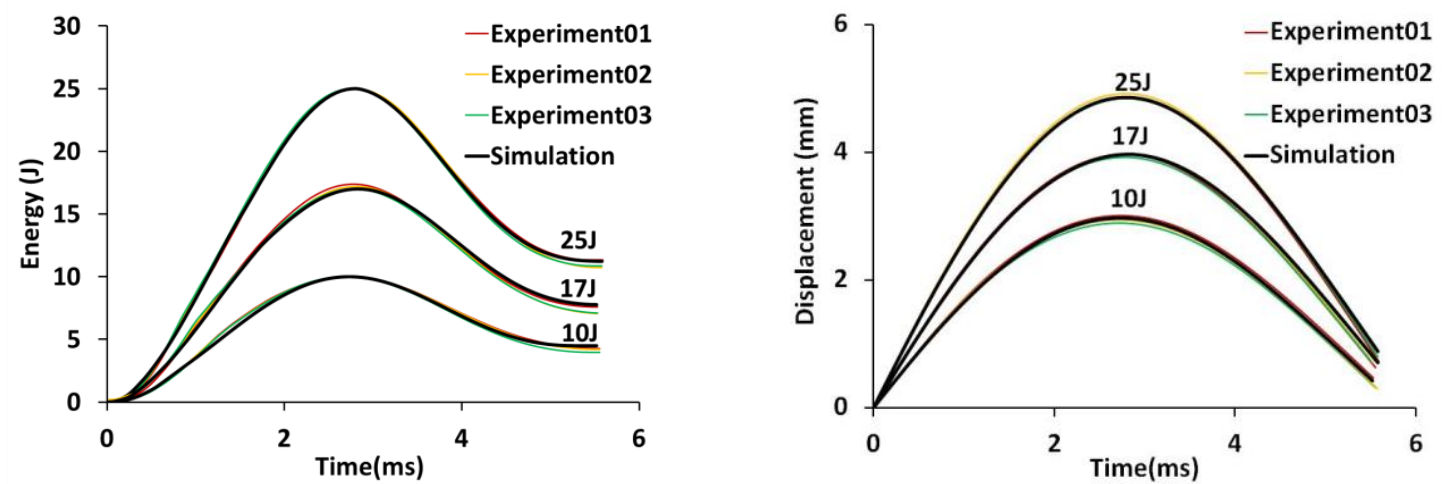
Fig. 23. (a) Absorbed energy versus time curves and (b) displacement evolution of impactor over time history attained from P\#2 specimens.

\subsection{Delamination}

The damage footprint of P\#2 specimens obtained from virtual impact tests at $10 \mathrm{~J}$ and $17 \mathrm{~J}$ are superimposed and compared with the corresponding C-scan results and shown in Figs. 24a and 24b, respectively. Good correlation was achieved

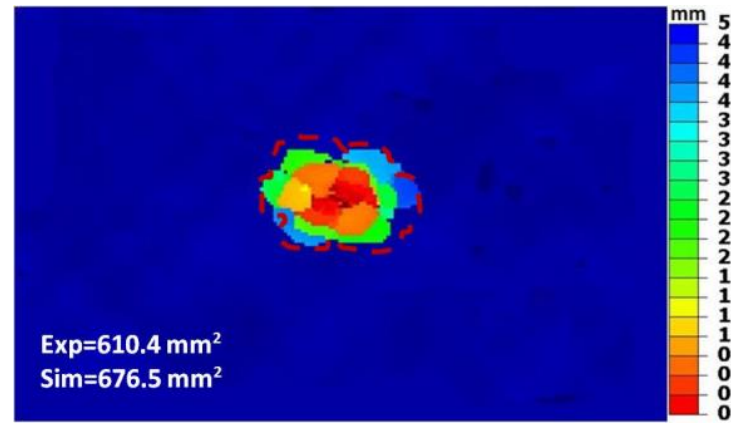

(a)

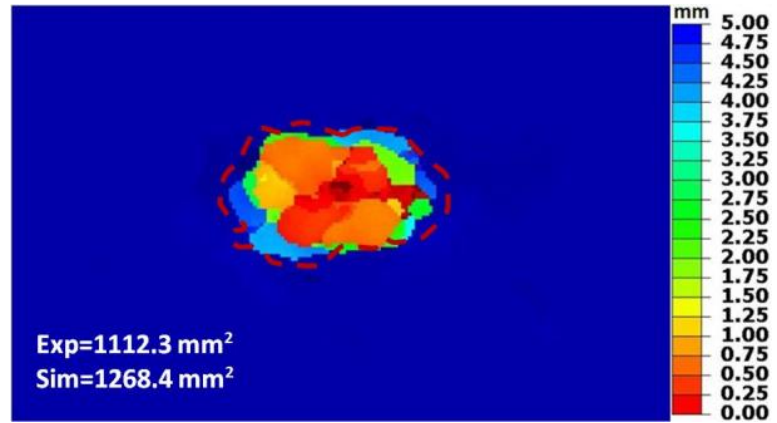

(b)

Fig. 24. Comparison of damage footprint obtained from C-scan and simulation (red dash line) for (a) $10 \mathrm{~J}$ and (b) $17 \mathrm{~J}$ impact energy cases.

The non-destructive results suggest that, generally, the delamination propagation direction was dominated by the lower ply. This phenomenon is illustrated in Fig. 25. In order to validate the ability of this predictive model to accurately capture delamination in composites, delamination at each interface is shown in Fig. 26a for the $25 \mathrm{~J}$ impact energy case. The delamination contour obtained from the virtual drop-weight impact test at $25 \mathrm{~J}$ energy level was compared with the corresponding delamination map attained using C-scanning and is shown in Fig. 26b. The comparison indicates that this damage model has excellent capability in predicting delamination caused by impact loading. 

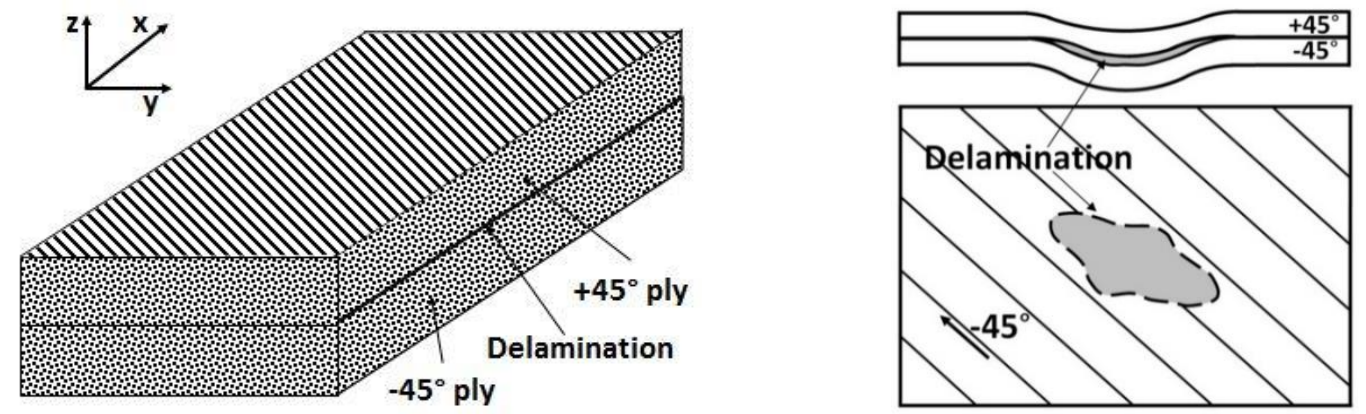

Fig. 25. Delamination orientation between two plies, favouring lower ply.
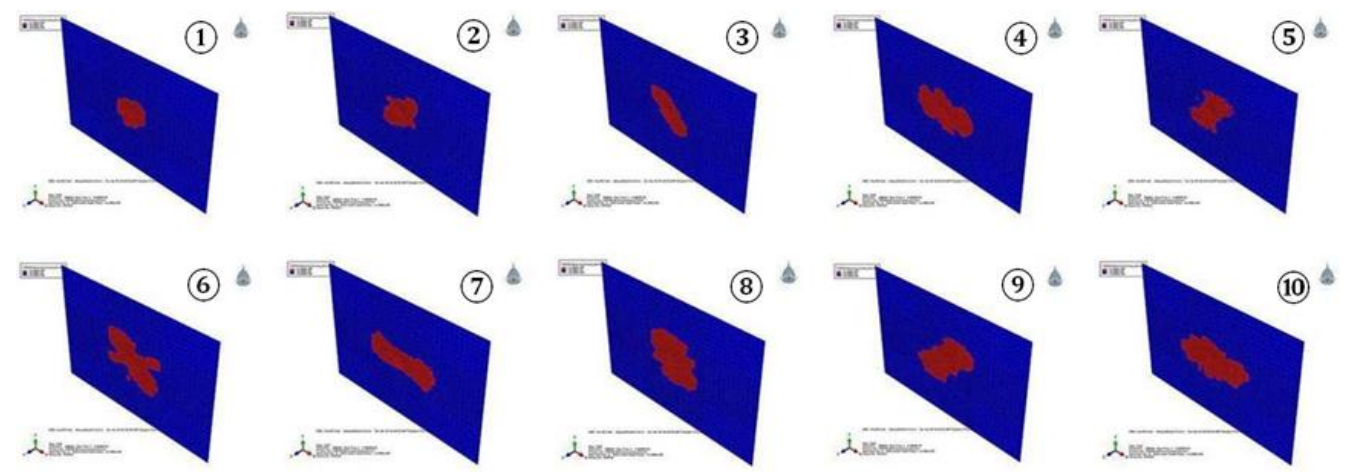

(a)

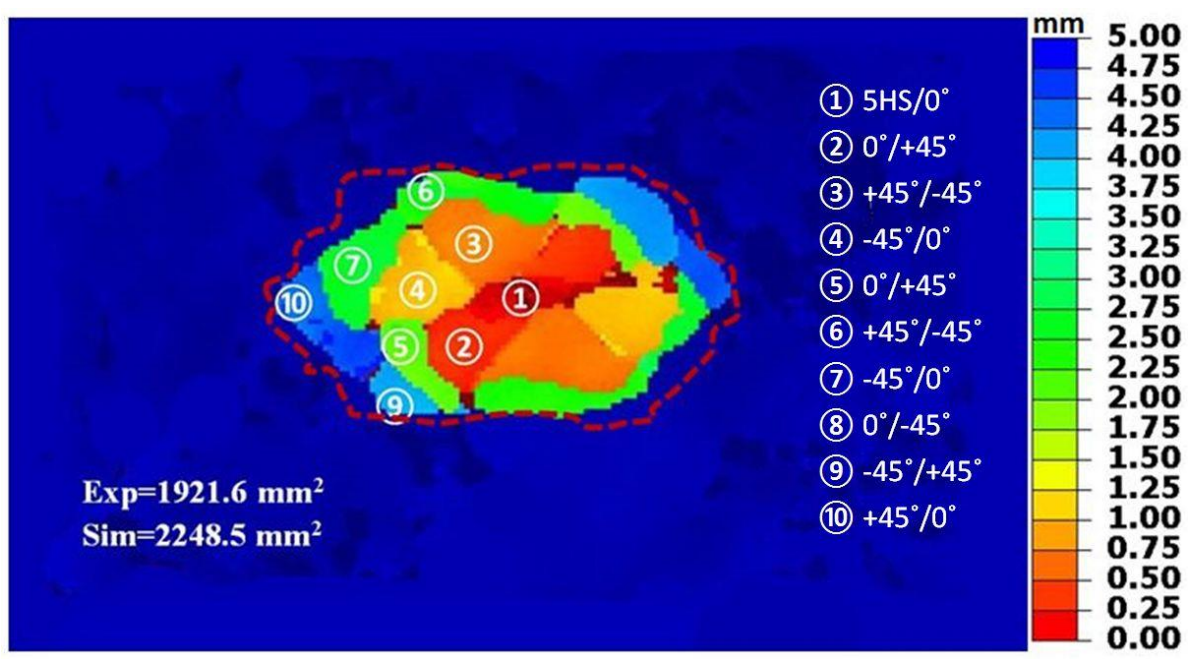

(b)

Fig. 26. (a) Delamination at each interface and (b) Comparison of damage footprint obtained from C-scan and simulation (red dash line). (The contour is the depth from the measuring layer to the top surface) 
To highlight the advantage of using hybrid unidirectional/woven carbon fibre reinforced composite laminates over unidirectional laminates, the validated computational model was used to compare the performance of pure unidirectional carbon-fibre reinforced composite laminates and hybrid unidirectional/woven carbon-fibre reinforced composite laminates. To represent a unidirectional laminate, the first sublaminate $(5 H S)$ of the lay-up $[5 H S / 0 / 0 /+45 /-45 / 0 / 0 / 0 /-45 /+45 / 0 / 0 / 0 /+45 /-$ 45/0/0/5HS] was substituted by an equally thick cross-ply (0/90), in which the surface-based cohesive behaviour was also applied to capture the potential for interfacial damage between $0^{\circ}$ ply and $90^{\circ}$ ply. The same substitution was made to the last sublaminate, Fig. 27.

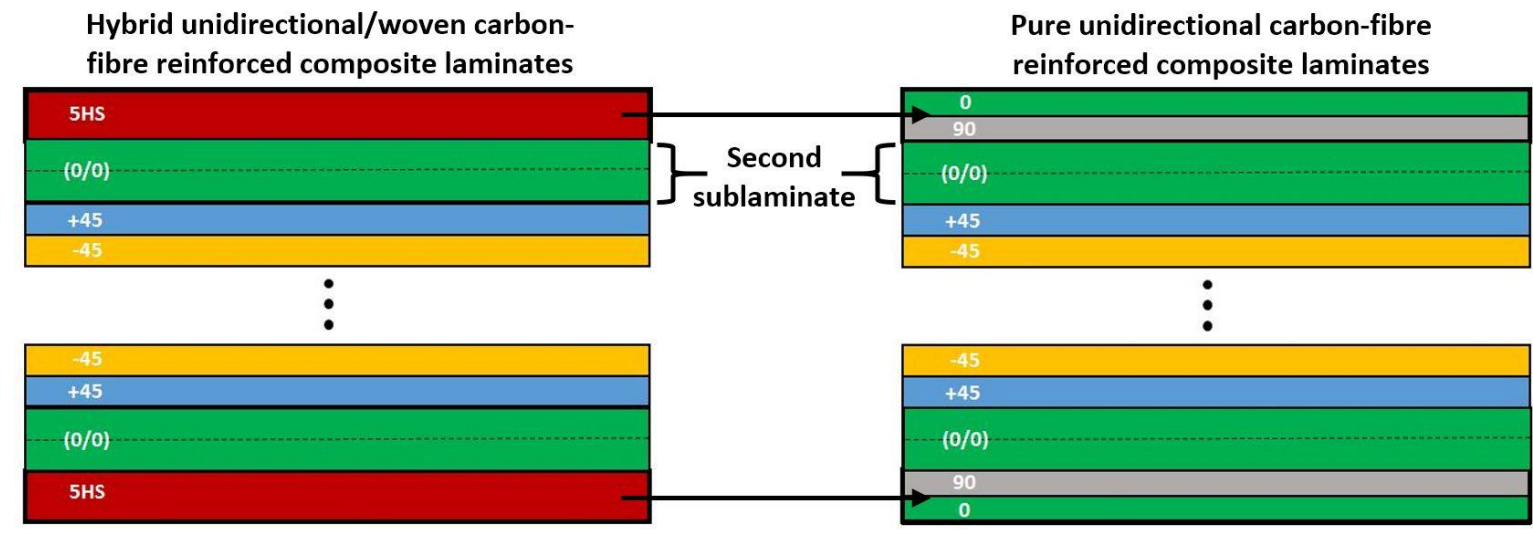

Fig. 27. Woven surface plies replacement, in hybrid unidirectional/woven carbon-fibre reinforced composite laminates, with a 0/90 cross-ply equivalent.

Figs. $28 \mathrm{a}$ and $28 \mathrm{~b}$ show comparative results including load-time history and absorbed energy-time curves, respectively. The load-displacement history indicates that the maximum loads presented by both types of composite laminates are close, while the pure unidirectional (PU) carbon-fibre reinforced composite laminates delivered a smaller displacement and higher reaction force (load) than the hybrid unidirectional/woven (U/W) carbon-fibre reinforced composite laminates. In Fig. 28b, the energy absorbed by the PU carbon-fibre reinforced composite laminates is $12.1 \mathrm{~J}$ which is higher than the $11.2 \mathrm{~J}$ energy absorbed by the hybrid U/W carbon-fibre reinforced composite laminates. The results suggested that the use of woven plies, in the outer layers, improves the performance of the hybrid U/W carbon-fibre reinforced composite laminates through less energy absorption although it is recognised that the hybrid laminates will have slightly lower bending stiffness. 


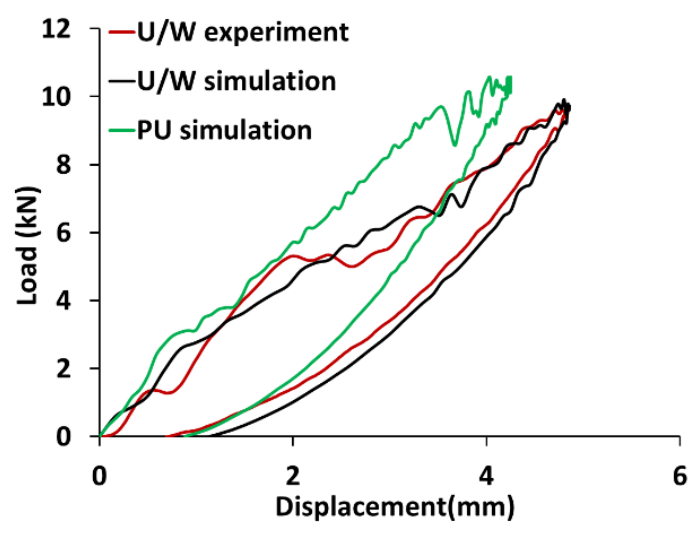

(a)

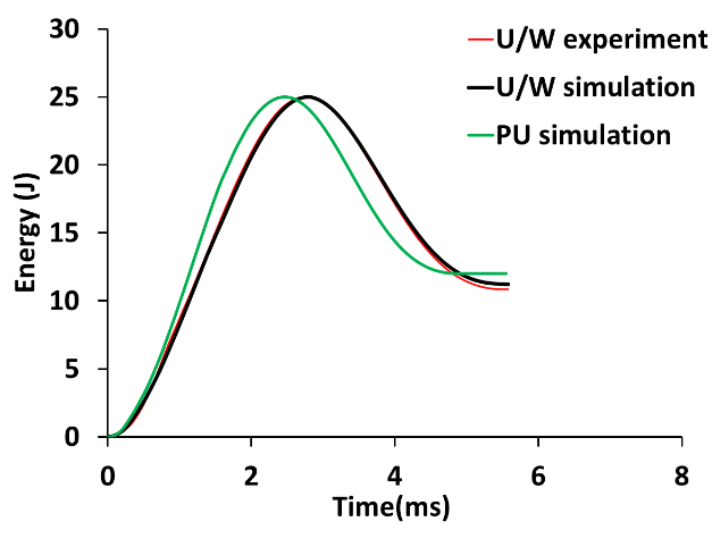

(b)

Fig. 28. Comparison of (a) load-displacement history and (b) absorbed energy-time curves obtained from pure unidirectional and hybrid unidirectional/woven carbon-fibre reinforced composite laminates.

A comparison of the second sub-laminate (0/0) matrix damage, shown in Fig. 29, indicates that pure unidirectional carbonfibre reinforced composite laminates generated more matrix damage than hybrid unidirectional/woven carbon-fibre reinforced composite laminates. In the pure unidirectional composite laminates, the damage area is a roughly circular shape. Damage areas presented by hybrid unidirectional/woven composites and pure unidirectional composites are similar, but unidirectional/woven composites showed slightly less damage than in pure unidirectional composites. Compared to woven composite plies, cracks can initiate and propagate more readily in the unidirectional carbon-fibre reinforced composite ply. These results confirm that the inclusion of woven plies in the top and bottom surfaces of composite structures can constrain crack propagation and reduce the damage caused by impact loading, thereby improving damage resistance. This strategy is also often used in the aerospace industry to minimise the potential for surface ply damage during drilling for mechanical fasteners.
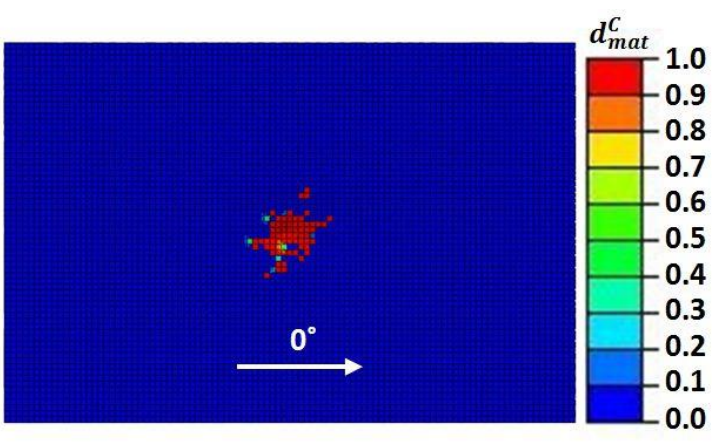

(a)
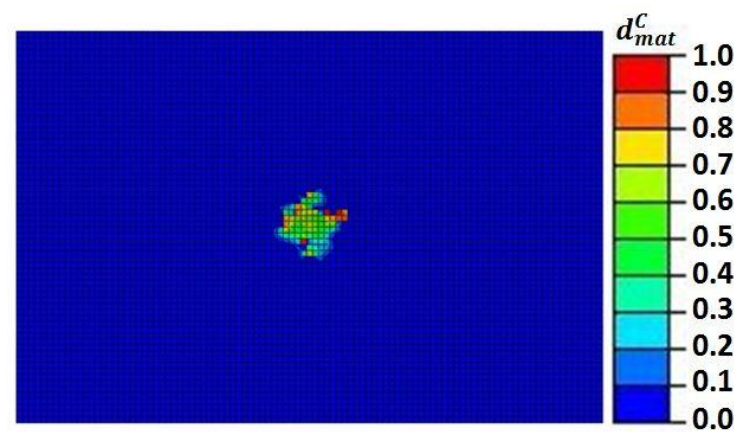

(b) 
Fig. 29. The matrix damage of second sub-laminate $(0 / 0)$ obtained from (a) pure unidirectional post-impact composite laminates and (b) hybrid unidirectional/woven post-impact composite laminates.

\section{Conclusion}

This work presented an experimental and numerical investigation into the impact response of hybrid composite laminates. An experimental programme showed that:

(1) In low velocity impact tests, maximum reaction force and damage area were shown to be linearly related to impact energy. However, the contact time was independent of impact energy and presented a constant value for each lay-up investigated.

(2) The specimen lay-up can affect the impact response of composite laminates by changing the overall bending stiffness. The involvement of $90^{\circ}$ plies not only reduced the response time but also promoted the growth of delamination along the transverse direction.

(3) Cross-sections, along different orientations, were examined from the impacted specimens. For the material system used in this study, the main failure mode observed in the impact event was delamination, with a small amount of matrix cracking, but no fibre breakage. Furthermore, no delamination was found at the interface between blocked plies.

(4) This work presented a damage model for predicting the impact response of mixed composite material architectures consisting of woven and unidirectional plies. The material response including load/energy-time curves and load-displacement curves were obtained from virtual drop-weight impact tests. The delamination and indentation introduced by low velocity impact were reproduced in the virtual impact test. Very good correlation was obtained between experimental results and simulation results.

(5) A comparative performance assessment was undertaken between the hybrid unidirectional/woven carbon-fibre reinforced composite laminates and equivalent pure unidirectional carbon-fibre reinforced composite laminates. 
The results showed that the use of woven plies on the top and bottom layers can reduce the extent of damage

during an impact event.

\section{Acknowledgement}

The corresponding author acknowledges the financial support provided by Bombardier and the Royal Academy of

Engineering. The authors would like to acknowledge Mr Dave Thompson and Mr Martin Gillen from the Northern Ireland

Advanced Composites and Engineering Centre (NIACE)/BAB Strategic Technology for their assistance with the experiment

testing.

\section{References}

[1] Guinard S, Allix O, Guédra-Degeorges D, Vinet A. A 3D damage analysis of low-velocity impacts on laminated composites. Compos Sci Technol, 2002;62:585-9.

[2] Riccio A, Luca A De, Felice G Di, Caputo F. Modelling the simulation of impact induced damage onset and evolution in composites. Compos Part B Eng, 2014;66:340-7.

[3] Balaganesan G, Chandra V. Energy absorption of repaired composite laminates subjected to impact loading. Compos Part B Eng, 2016;98:39-48.

[4] Her S-C, Liang Y-C. The finite element analysis of composite laminates and shell structures subjected to low velocity impact. Compos Struct, 2004;66:277-85.

[5] Kurs A. Effect of impactor shapes on the low velocity impact damage of sandwich composite plate : Experimental study and modelling. Compos Part B Eng, 2016;86:143-51.

[6] Dogan A, Arikan V. Low-velocity impact response of E-glass reinforced thermoset and thermoplastic based sandwich composites. Compos Part B Eng, 2017;127:63-9.

[7] Bouvet C, Castanié B, Bizeul M, Barrau JJ. Low velocity impact modelling in laminate composite panels with discrete interface elements. Int J Solids Struct, 2009;46:2809-21.

[8] Hongkarnjanakul N, Bouvet C, Rivallant S. Validation of low velocity impact modelling on different stacking sequences of CFRP laminates and influence of fibre failure. Compos Struct, 2013;106:549-59.

[9] Bandaru AK, Ahmad S. Modeling of progressive damage for composites under ballistic impact. Compos Part B Eng, 2016;93:75-87.

[10] Altilia SD, Valente T, Santulli C, Sarasini F, Tirill J, Touchard F, et al. Damage tolerance of carbon/flax hybrid composites subjected to low velocity impact. Compos Part B Eng, 2016;91:144-53.

[11] Aktaş M, Atas C, İçten BM, Karakuzu R. An experimental investigation of the impact response of composite laminates. Compos Struct, 2009;87:307-13.

[12] Evci C, Gülgeç M. An experimental investigation on the impact response of composite materials. Int J Impact Eng, 2012;43:40-51.

[13] Matzenmiller A, Lubliner J, Tylor RL. A constitutive model for anisotropic damage in fiber-composites. Mech Mater, 1995;20:125-52.

[14] Hallquist JO. LS-DYNA theory manul. Livermore Softw Technolodge Corp, 2006.

[15] Chang F-K, Chang K-Y. A progressive damage model for laminated composites containing stress concentrations. J Compos Mater, 1987;21:834-55.

[16] Shi Y, Swait T, Soutis C. Modelling damage evolution in composite laminates subjected to low velocity impact. Compos Struct, 2012;94:2902-13. 
[17] Shi Y, Pinna C, Soutis C. Modelling impact damage in composite laminates: A simulation of intra- and inter-laminar cracking. Compos Struct, 2014;114:10-9.

[18] Ansari M, Chakrabarti A. Impact behavior of FRP composite plate under low to hyper velocity impact. Compos Part B Eng, 2016;95:462-74.

[19] Donadon MV, Iannucci L, Falzon BG, Hodgkinson JM, de Almeida SFM. A progressive failure model for composite laminates subjected to low velocity impact damage. Comput Struct, 2008;86:1232-52.

[20] Donadon MV, de Almeida SFM, Arbelo MA, de Faria AR. A Three-Dimensional Ply Failure Model for Composite Structures. Int J Aerosp Eng, 2009;2009:1-22.

[21] Faggiani A, Falzon BG. Predicting low-velocity impact damage on a stiffened composite panel. Compos Part A Appl Sci Manuf, 2010;41:737-49.

[22] Falzon BG, Apruzzese P. Numerical analysis of intralaminar failure mechanisms in composite structures. Part I: FE implementation. Compos Struct, 2011;93:1039-46.

[23] Falzon BG, Apruzzese P. Numerical analysis of intralaminar failure mechanisms in composite structures. Part II: Applications. Compos Struct, 2011;93:1047-53.

[24] Bouvet C, Rivallant S, Barrau JJ. Low velocity impact modeling in composite laminates capturing permanent indentation. Compos Sci Technol, 2012;72:1977-88.

[25] Tan W, Falzon BG, Chiu LNS, Price M. Predicting low velocity impact damage and Compression-AfterImpact (CAI) behaviour of composite laminates. Compos Part A Appl Sci Manuf, 2015;71:212-26.

[26] Tan W, Falzon BG, Price M, Liu H. The role of material characterisation in the crush modelling of thermoplastic composite structures. Compos Struct, 2016;153:914-27.

[27] Tan W, Falzon BG. Modelling the crush behaviour of thermoplastic composites. Compos Sci Technol, 2016;134:57-71.

[28] Abaqus 6.12 documentation. Dassault Systèmes. Provid Rhode Island, USA, 2012.

[29] Zhong S, Guo L, Liu G, Lu H, Zeng T. A continuum damage model for three-dimensional woven composites and finite element implementation. Compos Struct, 2015;128:1-9.

[30] Donadon MV, Falzon BG, Iannucci L, Hodgkinson JM. A 3-D micromechanical model for predicting the elastic behaviour of woven laminates. Compos Sci Technol, 2007;67:2467-77.

[31] Panettieri E, Fanteria D, Montemurro M, Froustey C. Low-velocity impact tests on carbon/epoxy composite laminates: A benchmark study. Compos Part B Eng, 2016;107:9-21.

[32] Shyr T-W, Pan Y-H. Impact resistance and damage characteristics of composite laminates. Compos Struct, 2003;62:193-203.

[33] Ravandi M, Teo WS, Tran LQN, Yong MS, Tay TE. Low velocity impact performance of stitched flax/ epoxy composite laminates. Compos Part B Eng, 2017;117:89-100.

[34] Selver E, Potluri P, Hogg P, Soutis C. Impact damage tolerance of thermoset composites reinforced with hybrid commingled yarns. Compos Part B Eng, 2016;91:522-38.

[35] Williams C, Summerscales J, Grove S. Resin infusion under flexible tooling (RIFT): A review. Compos Part A Appl Sci Manuf, 1996;27:517-24.

[36] Govignon Q, Bickerton S, Morris J, Kelly PA. Full field monitoring of the resin flow and laminate properties during the resin infusion process. Compos Part A Appl Sci Manuf, 2008;39:1412-26.

[37] Donadon MV, Falzon BG, Iannucci L, Hodgkinson JM. Intralaminar toughness characterisation of unbalanced hybrid plain weave laminates. Compos Part A Appl Sci Manuf, 2007;38:1597-611.

[38] Giannaros E, Kotzakolios T, Tsantzalis S, Kostopoulos V. Implementation and calibration of meso-scale modeling technique for simulation of tensile behavior of fabric materials. Compos Part B Eng, 2017;119:1-9.

[39] Airbus Standard. Determination of compression strength after impact. AITM 1-0010, 2010.

[40] ASTM. Standard Test Method for Measuring the Damage Resistance of a Fiber-Reinforced Polymer Matrix Composite to a Drop-Weight Impact Event. D7136/D7136M-05, West Conshohocken, PA, 2005:1-16.

[41] Castellano A, Fraddosio A, Piccioni MD. Ultrasonic goniometric immersion tests for the characterization of fatigue post-LVI damage induced anisotropy superimposed to the constitutive anisotropy of polymer composites. Compos Part B Eng, 2017;116:122-36.

[42] Khomenko A, Karpenko O, Koricho EG, Haq M, Cloud GL, Udpa L. Quantitative comparison of optical transmission scanning with conventional techniques for NDE of impact damage in GFRP composites. Compos Part B Eng, 2017;123:92-104.

[43] Jespersen KM, Zangenberg J, Lowe T, Withers PJ, Mikkelsen LP. Fatigue damage assessment of unidirectional non-crimp fabric reinforced polyester composite using X-ray computed tomography. Compos Sci Technol, 2016;136:94-103.

[44] Hou JP, Jeronimidis G. Bending stiffness of composite plates with delamination. Compos Part A Appl Sci Manuf, 2000;31:121-32. 
[45] Tsai WS, Melo JDD. Composite Materials Design and Testing-Unlocking mystery with invariants. Stanford, USA: DEStech Publications, Inc; 2015.

[46] Kachanov LM. Time of rupture process under creep conditions. Izy Akad Nank SSR Otd Tech Nauk, 1958;8:26-31.

[47] Rabotnov YN. Creep rupture. Proc XII Int Cong Appl Mech, 1968.

[48] Tan W, Falzon BG. Modelling the nonlinear behaviour and fracture process of AS4/PEKK thermoplastic composite under shear loading. Compos Sci Technol, 2016;126:60-77.

[49] Chiu LNS, Falzon BG, Ruan D, Xu S, Thomson RS, Chen B, et al. Crush responses of composite cylinder under quasi-static and dynamic loading. Compos Struct, 2015;131:90-8.

[50] Chiu LNS, Falzon BG, Chen B, Yan W. Validation of a 3D damage model for predicting the response of composite structures under crushing loads. Compos Struct, 2016;147:65-73.

[51] Puck A, Schürmann H. Failure analysis of FRP laminates by means of physically based phenomenological models. Compos Sci Technol, 1998;58:1045-67.

[52] Catalanotti G, Camanho PP, Marques AT. Three-dimensional failure criteria for fiber-reinforced laminates. Compos Struct, 2013;95:63-79.

[53] Daniel IM, Luo JJ, Schubel PM. Three-dimensional characterization of textile composites. Compos Part B Eng, 2008;39:13-9.

[54] Benzeggagh ML, Kenane M. Measurement of mixed-mode delamination fracture toughness of unidirectional glass/epoxy composites with mixed-mode bending apparatus. Compos Sci Technol, 1996;56:439-49.

[55] ASTM. Standard Test Method for Mixed Mode I-Mode II Interlaminar Fracture Toughness of Unidirectional Fiber Reinforced Polymer Matrix Composites. D6671/D6671M-03, West Conshohocken, PA, 2003.

[56] Turon A, Camanho PP, Costa J, Renart J. Accurate simulation of delamination growth under mixed-mode loading using cohesive elements: Definition of interlaminar strengths and elastic stiffness. Compos Struct, 2010;92:1857-64.

[57] Turon A, Dávila CG, Camanho PP, Costa J. An engineering solution for mesh size effects in the simulation of delamination using cohesive zone models. Eng Fract Mech, 2007;74:1665-82.

[58] ASTM. Standard Test Method for Mode I Interlaminar Fracture Toughness of Unidirectional FiberReinforced Polymer Matrix Composites. D5528-01, West Conshohocken, PA, 2004.

[59] ASTM. Standard Test Method for Determination of the Mode II Interlaminar Fracture Toughness of Unidirectional Fiber-Reinforced Polymer Matrix Composites. D7905/D7905M-14, West Conshohocken, PA, 2014.

[60] Pinho ST, Robinson P, Iannucci L. Fracture toughness of the tensile and compressive fibre failure modes in laminated composites. Compos Sci Technol, 2006;66:2069-79.

[61] Joki RK, Grytten AF, Hayman B. Nonlinear response in glass fibre non-crimp fabric reinforced vinylester composites. Compos Part B Eng, 2015;77:105-11.

[62] Schuecker C, Davidson BD. Evaluation of the accuracy of the four-point bend end-notched flexure test for mode II delamination toughness determination. Compos Sci Technol, 2000;60:2137-46. 
